ARTICLE

DOI: $10.1038 / \mathrm{s} 41467-017-00596-3$

\title{
Hydrodeoxygenation of water-insoluble bio-oil to alkanes using a highly dispersed Pd-Mo catalyst
}

\author{
Haohong Duan (1) 1,2, Juncai Dong (1) ${ }^{3}$, Xianrui Gu ${ }^{4}$, Yung-Kang Peng ${ }^{2}$, Wenxing Chen ${ }^{5}$, Titipong Issariyakul ${ }^{6}$, \\ William K. Myers (1) ${ }^{1}$, Meng-Jung Li ${ }^{2}, \mathrm{Ni} \mathrm{Yi}^{1}$, Alexander F.R. Kilpatrick${ }^{1}$, Yu Wang ${ }^{7}$, Xusheng Zheng ${ }^{8}$, Shufang Ji ${ }^{5}$, \\ Qian Wang 9 , Junting Feng 9 , Dongliang Chen ${ }^{3}$, Yadong $\mathrm{Li}^{5}$, Jean-Charles Buffet ${ }^{1}$, Haichao Liu ${ }^{4}$, \\ Shik Chi Edman Tsang (i) ${ }^{2} \&$ Dermot $\mathrm{O}^{\prime}$ Hare $^{1}{ }^{1}$
}

Bio-oil, produced by the destructive distillation of cheap and renewable lignocellulosic biomass, contains high energy density oligomers in the water-insoluble fraction that can be utilized for diesel and valuable fine chemicals productions. Here, we show an efficient hydrodeoxygenation catalyst that combines highly dispersed palladium and ultrafine molybdenum phosphate nanoparticles on silica. Using phenol as a model substrate this catalyst is $100 \%$ effective and $97.5 \%$ selective for hydrodeoxygenation to cyclohexane under mild conditions in a batch reaction; this catalyst also demonstrates regeneration ability in long-term continuous flow tests. Detailed investigations into the nature of the catalyst show that it combines hydrogenation activity of Pd and high density of both Brønsted and Lewis acid sites; we believe these are key features for efficient catalytic hydrodeoxygenation behavior. Using a wood and bark-derived feedstock, this catalyst performs hydrodeoxygenation of lignin, cellulose, and hemicellulose-derived oligomers into liquid alkanes with high efficiency and yield.

\footnotetext{
${ }^{1}$ Chemistry Research Laboratory, Department of Chemistry, University of Oxford, 12 Mansfield Road, Oxford OX1 3TA, UK. ${ }^{2}$ The Wolfson Catalysis Centre, Department of Chemistry, University of Oxford, Oxford OX1 3QR, UK. ${ }^{3}$ Beijing Synchrotron Radiation Facility, Institute of High Energy Physics, Chinese Academy of Sciences, 19B Yuquan Road, Shijingshan District, Beijing 100049, China. ${ }^{4}$ Beijing National Laboratory for Molecular Sciences, College of Chemistry and Molecular Engineering, Peking University, Beijing 100871, China. ${ }^{5}$ Department of Chemistry and Collaborative Innovation Center for Nanomaterial Science and Engineering, Tsinghua University, 30 Shuangqing Rd, Haidian Qu, Beijing Shi 100084, China. ${ }^{6}$ Product \& Technology Development Center, SCG Packaging Public Company Limited, 19 Moo 19 Seang-Xuto Road, ThaPha, BanPong, Ratchaburi 70110, Thailand. ${ }^{7}$ Shanghai Synchrotron Radiation Facilities, Shanghai Institute of Applied Physics, Chinese Academy of Science, 239 Zhangheng Road, Pudong New District, Shanghai 201204, China. ${ }^{8}$ National Synchrotron Radiation Laboratory, University of Science and Technology of China, 42 Hezuohua Road, Hefei, Anhui 230029, China. ${ }^{9}$ State Key Laboratory of Chemical Resource Engineering, Beijing University of Chemical Technology, 15 Bei San Huan East Road, Beijing 100029, China. Haohong Duan and Juncai Dong contributed equally to this work. Correspondence and requests for materials should be addressed to

S.C.E.T. (email: edman.tsang@chem.ox.ac.uk) or to D.O'H. (email: dermot.ohare@chem.ox.ac.uk)
} 


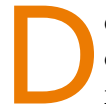

ecreasing petroleum deposits combined with conversely climbing global demand and environmental concern makes it critical to develop fuel and chemical production processes based on renewable resources ${ }^{1}$. Lignocellulosic biomass, including cellulose, hemicellulose, and lignin, is the most abundantly available and cost-effective carbon reservoir that can be used to produce renewable fuel and high added-value chemicals ${ }^{2}$. Compared with biomass fractionation, which requires extensive pre-treatment and following hydrolysis, flash pyrolysis is a cheaper process for the production of upgradable bio-oil from lignocellulose, and offers potential for lignin utilization ${ }^{3,4}$. However, the bio-oil also contains high oxygen content (up to 60 $w t \%)$ and necessitates further catalytic upgrading, preferably via hydrodeoxygenation (HDO), before use in hydrocarbon fuel or chemical production ${ }^{5}$. The water soluble fraction of bio-oil mainly involves carbohydrates that could be catalytically converted into hydroxymethylfurfural ${ }^{6}, 7$, levulinic acid $^{8}$, and monofunctional hydrocarbons ${ }^{9,}{ }^{10}$; these platform chemicals can be further converted to hydrocarbons via HDO. By comparison, the water-insoluble bio-oil (WIBO) often contains a large variety of products derived from lignin, cellulose, and hemicellulose in the form of oligomers with molecular weight up to $5000 \mathrm{Da}^{5}$. The complexity of WIBO composition and the chemical inertness of the oligomers present therefore pose a great challenge for any HDO catalyst.

In recent years, bifunctional metal-acid catalysts have been developed, showing high efficiency in HDO reaction for hydrocarbon fuel production from lignin ${ }^{11-17}$. Lercher and co-workers have made important contributions on the design of an efficient combination of metal-catalyzed hydrogenation and acid- catalyzed deoxygenation for highly selective HDO of phenols to cyclohexanes ${ }^{11}, 15$. Both the Dyson and Leitner groups have made impressive progress on the development of high performance catalyst for the HDO of lignin-derived phenols using combinations of metal nanoparticles and acidic ionic liquids ${ }^{8,}$ 17. In spite of the growing number of metal-acid combinations, the successful productions of alkanes using these bifunctional metal-acid catalysts have been mostly used for single-component lignin-derived monomers. The conversion of lignin into alkanes has been realized in a rare case via a two-step process, involving catalytic cleavage of the $\mathrm{C}-\mathrm{O}-\mathrm{C}$ bonds and subsequent hydrogenolysis/ hydrogenation ${ }^{18}$. Very recently, the production of alkanes, with mass yield up to $28.1 \mathrm{wt} \%$, was reported via HDO from raw lignocellulose containing cellulose, hemicellulose, and lignin by using a $\mathrm{Pd} / \mathrm{NbOPO}_{4}$ bifunctional catalyst. However, the mass yield of alkyl cyclohexanes converted from lignin was only up to $5.1 \mathrm{wt} \%{ }^{19}$. Efficient HDO requires the design and synthesis of a bifunctional catalyst containing active metal and both Brønsted and Lewis acid sites. Recent reports showed that atomically dispersed metal may demonstrate higher activity and efficiency compared with nanoparticles in heterogeneous reactions ${ }^{20-22}$. It is also believed increased Brønsted acid sites favor increasing alkane selectivities ${ }^{16,23}$, and additional Lewis acid sites may help catalyze the reaction through initial binding of the oxygenated substrates and subsequent cleavage of the $\mathrm{C}-\mathrm{O}$ linkages ${ }^{19}$.

Herein, we present a highly dispersed Pd-Mo catalyst that encompasses a combination of highly dispersed $\mathrm{Pd}$ and ultrafine Mo phosphate nanoparticles on silica $\left(\mathrm{Pd} / \mathrm{m}-\mathrm{MoO}_{3}-\mathrm{P}_{2} \mathrm{O}_{5} / \mathrm{SiO}_{2}\right)$, in which $\mathrm{m}$ represents mixed-valent Mo. In batch reaction, this catalyst exhibits high activity (99\%) for the catalytic HDO of
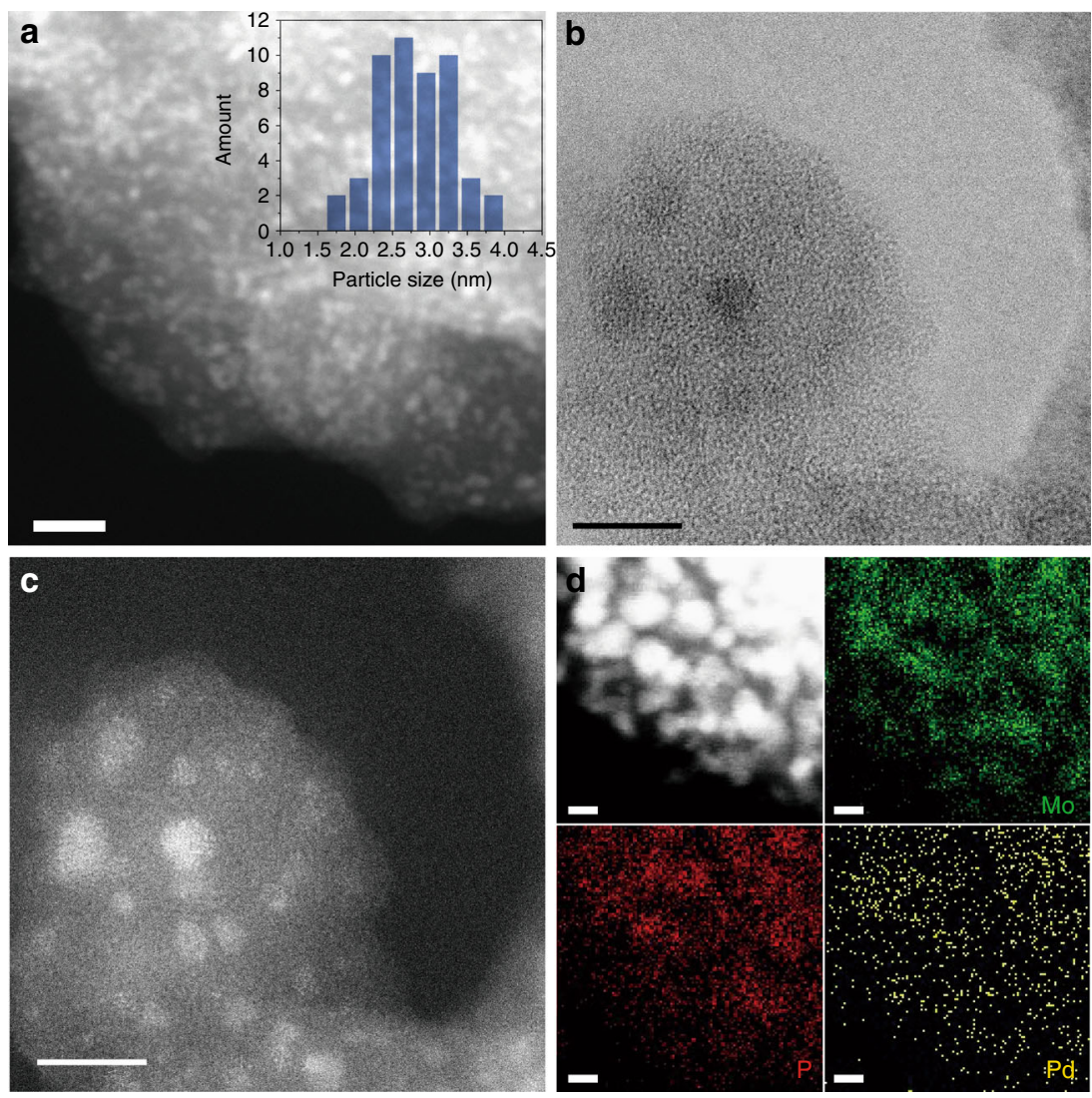

Fig. 1 Characterizations of the $\mathrm{Pd} / \mathrm{m}-\mathrm{MoO}_{3}-\mathrm{P}_{2} \mathrm{O}_{5} / \mathrm{SiO}_{2}$ catalyst. a HAADF-STEM image of $\mathrm{Pd} / \mathrm{m}-\mathrm{MoO}_{3}-\mathrm{P}_{2} \mathrm{O}_{5} / \mathrm{SiO}_{2}$. Inset shows the size distribution of the nanoparticles. Scale bar equals $20 \mathrm{~nm}$. b Aberration-corrected ABF scanning transmission electron microscope image and c corresponding HAADFSTEM image of $\mathrm{Pd} / \mathrm{m}-\mathrm{MoO}_{3}-\mathrm{P}_{2} \mathrm{O}_{5} / \mathrm{SiO}_{2}$. Scale bars equal $5 \mathrm{~nm}$. d STEM-EDS elemental mapping results for $\mathrm{Pd} / \mathrm{m}-\mathrm{MoO}_{3}-\mathrm{P}_{2} \mathrm{O}_{5} / \mathrm{SiO}{ }_{2}$, showing a homogeneous distribution of Mo and $\mathrm{P}$ elements within nanoparticles and highly dispersed Pd. Scale bar equals $3 \mathrm{~nm}$ 
a

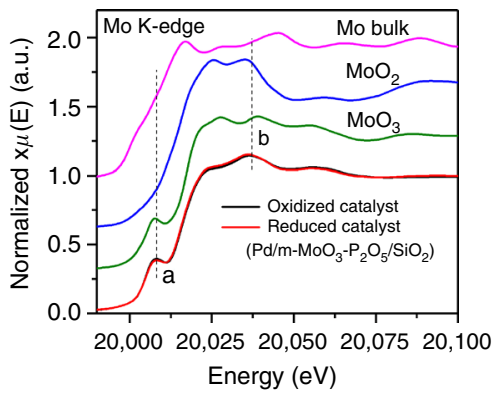

d

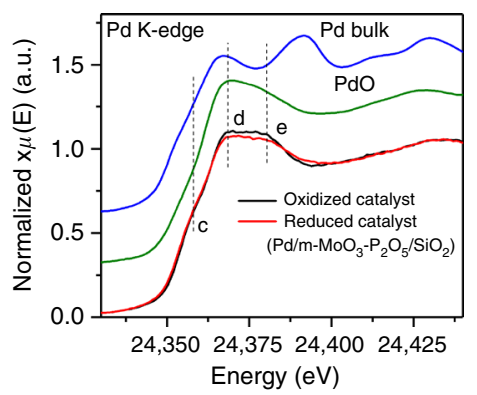

g

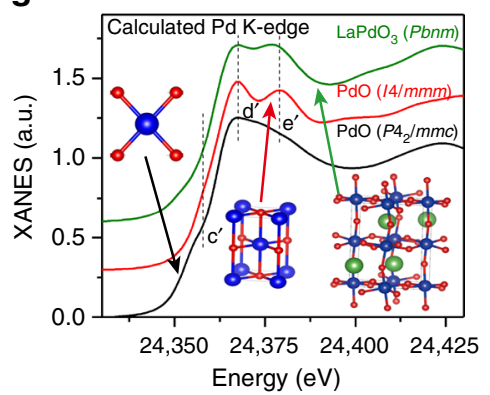

b

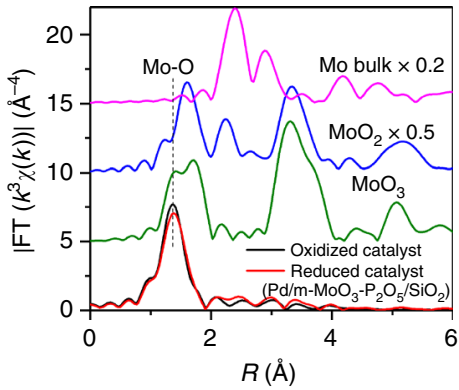

e

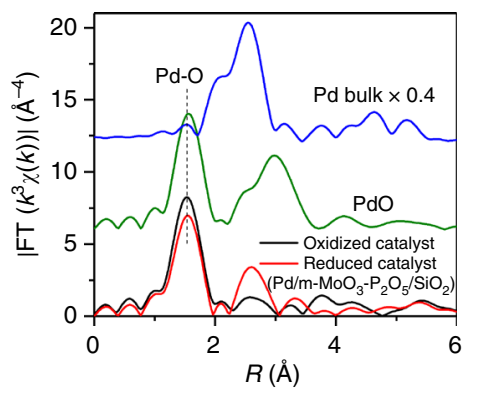

h

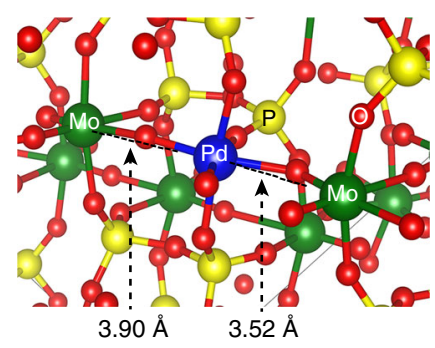

C

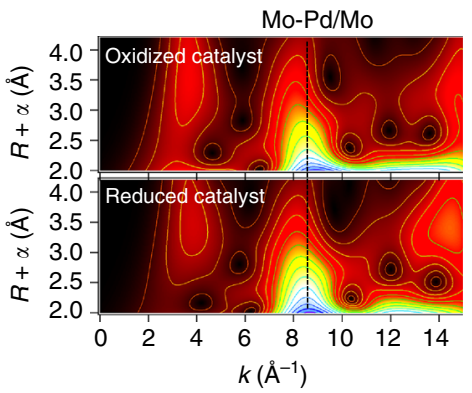

f
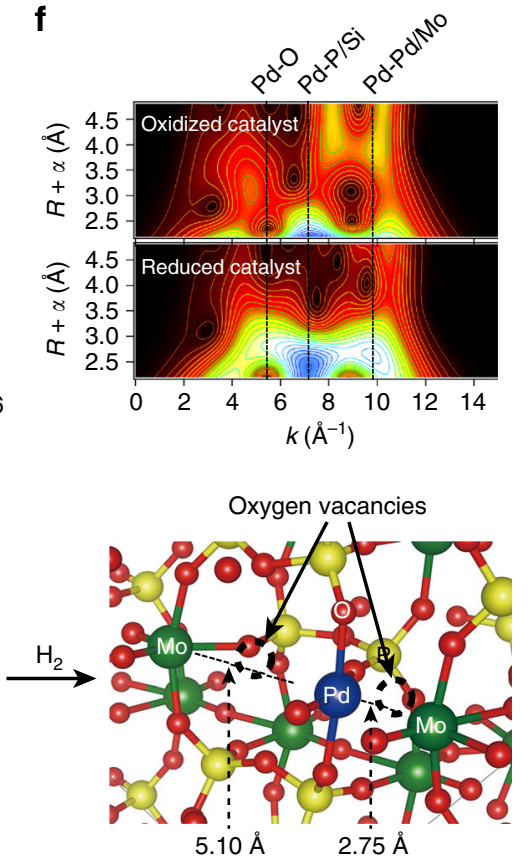

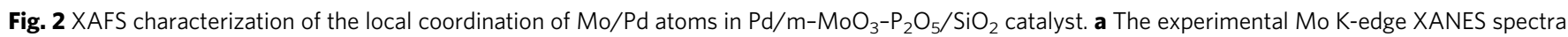

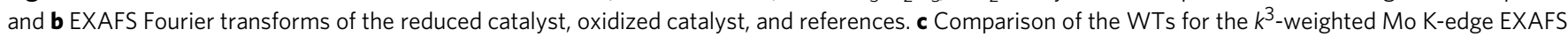
signals for the high coordination shells in oxidized catalyst and reduced catalyst. d The experimental Pd K-edge XANES spectra and e EXAFS Fourier transforms of reduced catalyst, oxidized catalyst, and references. $\mathbf{f}$ Comparison of the WTs for the $k^{3}$-weighted Pd K-edge EXAFS signals for the high

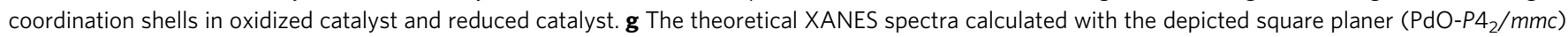
and distorted octahedral ( $\mathrm{PdO}-14 / \mathrm{mmm}$ and $\mathrm{LaPdO}_{3}-\mathrm{Pbnm}$ ) structures. $\mathbf{h}$ Schematic representation of structural modulation due to the production of oxygen vacancies in the oxygen network by $\mathrm{H}_{2}$ reduction. The vertical dashed lines are drawn to guide the eye

phenol to cyclohexane in very mild conditions $(383 \mathrm{~K}, 1 \mathrm{MPa})$. Furthermore, it shows good re-usability in continuous flow reaction conditions for $419 \mathrm{~h}$. Characterization studies show that the efficient HDO ability may originate from the cooperative effects between highly dispersed Pd, high Brønsted and Lewis acid sites. By feeding wood and bark-derived WIBO containing large amounts of lignocellulosic oligomers, the catalyst not only completely converts phenolic monomers to cyclohexanes, but also achieves HDO of lignin, cellulose, and hemicellulose-derived oligomers into cyclohexanes, hexane, and pentane in 13.4, 5.1, and $7.4 \mathrm{wt} \%$, respectively, with total mass yield up to $29.6 \mathrm{wt} \%$ and carbon yield up to $46.3 \%$.

\section{Results}

Catalysts synthesis and characterizations. The solid catalyst, $\mathrm{Pd} /$ $\mathrm{m}-\mathrm{MoO}_{3}-\mathrm{P}_{2} \mathrm{O}_{5} / \mathrm{SiO}_{2}$, was prepared using a wet-impregnation method (see "Methods" for preparation). Transmission electron microscopy (TEM) image of the $\mathrm{Pd} / \mathrm{m}-\mathrm{MoO}_{3}-\mathrm{P}_{2} \mathrm{O}_{5} / \mathrm{SiO}_{2}$ (Supplementary Fig. 1) shows ultrafine, electron-rich $\mathrm{m}-\mathrm{MoO}_{3}-\mathrm{P}_{2} \mathrm{O}_{5}$ nanoparticles supported on an amorphous $\mathrm{SiO}_{2}$ support. A highangle annular dark-field scanning transmission electron microscopy (HAADF-STEM) image (Fig. 1a) shows these ultrafine $\mathrm{m}-\mathrm{MoO}_{3}-\mathrm{P}_{2} \mathrm{O}_{5}$ nanoparticles with high coverage and size of 2.8 $\pm 1.0 \mathrm{~nm}$ (inset, Fig. 1a). Inductively coupled plasma mass spectrometry (ICP-AES) analysis showed a Mo:P molar ratio of ca. 1:1 (Supplementary Table 1), which is consistent with Energy Dispersive X-ray spectroscopy (EDXS) data (Supplementary Fig. 2). Aberration-corrected annular bright-field (ABF) scanning transmission electron microscope image (Fig. 1b) and corresponding HAADF-STEM image (Fig. 1c) clearly show that the $\mathrm{m}-\mathrm{MoO}_{3}-\mathrm{P}_{2} \mathrm{O}_{5}$ nanoparticles do not form a crystalline lattice. Together with powder X-ray diffractogram (PXRD) data (Supplementary Fig. 3), these results suggest that the $\mathrm{m}-\mathrm{MoO}_{3}-\mathrm{P}_{2} \mathrm{O}_{5}$ nanoparticles are crystallographically disordered. Elemental mapping revealed that $\mathrm{Mo}$ and $\mathrm{P}$ are well dispersed throughout individual $\mathrm{m}-\mathrm{MoO}_{3}-\mathrm{P}_{2} \mathrm{O}_{5}$ nanoparticles. The structure of the $\mathrm{m}-\mathrm{MoO}_{3}-\mathrm{P}_{2} \mathrm{O}_{5}$ nanoparticles was further investigated with the help of multinuclear solid-state nuclear magnetic resonance (NMR) spectroscopy. The ${ }^{31} \mathrm{P}$ solid-state magic angle spinning 
(MAS) NMR spectrum of a sample of the $\mathrm{Pd} / \mathrm{m}-\mathrm{MoO}_{3}-\mathrm{P}_{2} \mathrm{O}_{5} /$ $\mathrm{SiO}_{2}$ exhibits a single resonance centered at $\delta=-5.5 \mathrm{ppm}$ (Supplementary Fig. 4), the ${ }^{31} \mathrm{P}$ chemical shift matches that of a $\mathrm{MoO}_{3}-\mathrm{P}_{2} \mathrm{O}_{5}$ glass with Mo:P molar ratio ca. $1^{24,25}$. A strong absorption band at ca. $966 \mathrm{~cm}^{-1}$ in the Raman spectrum (Supplementary Fig. 5) can be assigned to a terminal $\nu(\mathrm{Mo}=\mathrm{O})$ in a $\mathrm{MoO}_{6}$ octahedra ${ }^{25}$. The data suggest that this glassy structure consists of chains of inter-connected $\mathrm{PO}_{4}$ tetrahedra and $\mathrm{MoO}_{6}$ octahedra linked via Mo-O-P bridges.

$\mathrm{X}$-ray absorption fine structure analysis. In addition to Mo and P elements, ICP-AES (Supplementary Table 1) and EDXS (Supplementary Fig. 2) data also show the presence of $\mathrm{Pd}$ in $\mathrm{Pd} /$ $\mathrm{m}-\mathrm{MoO}_{3}-\mathrm{P}_{2} \mathrm{O}_{5} / \mathrm{SiO}_{2}$ (0.48 wt\% from ICP-AES). The Pd signal is highly dispersed according to elemental mapping studies (Fig. 1d), and that the absence of Bragg diffraction of Pd from PXRD (Supplementary Fig. 3), these suggest Pd is presented in very small size. Due to the similar atomic number of $\mathrm{Pd}$ and $\mathrm{Mo}$, it is difficult to distinguish Pd using the intensity information in the HAADF-STEM image. To understand the coordination environment and chemical states of $\mathrm{Pd}$ in $\mathrm{Pd} / \mathrm{m}-\mathrm{MoO}_{3}-\mathrm{P}_{2} \mathrm{O}_{5} /$ $\mathrm{SiO}_{2}$, X-ray absorption near-edge structure (XANES) and extended X-ray absorption fine structure (EXAFS) spectroscopies were carried out. For clear comparison, $\mathrm{Pd} / \mathrm{m}-\mathrm{MoO}_{3}-\mathrm{P}_{2} \mathrm{O}_{5} / \mathrm{SiO}_{2}$ is labeled as reduced catalyst, and corresponding $\mathrm{H}_{2}$ treating precursor is labeled as oxidized catalyst. The Mo K-edge XANES spectrum for reduced catalyst shows a notable shoulder peak (denoted as a) in the pre-edge region (Fig. 2a) as $\mathrm{MoO}_{3}$, suggesting the formation of strongly distorted $\mathrm{MoO}_{6}$ octahedra having $\mathrm{Mo}=\mathrm{O}$ bond $^{26}$, in good agreement with the Raman results. The average valence of the Mo ions in the reduced catalyst is estimated to be ca. 5.5 using the linear relation between the Mo oxidation state and the energy position of feature $\mathrm{b}^{27}$, indicating the possible existence of mixed-valent $\mathrm{Mo}^{5 / 6+}$ oxide states. The Pd K-edge XANES spectrum is found to exhibit two well-defined features including a shoulder peak $\mathrm{c}$ and a doublet peak ( $\mathrm{d}$ and e) at the white line (Fig. 2d); our XANES simulation reveals that the shoulder peak c can be considered to be the fingerprint of $\mathrm{Pd}^{2+}$ in square planar coordination, while the intensity of feature e is higher for Pd ions in distorted octahedral coordination than for the square planar coordination (Fig. 2g), consistent with XANES results in the literature ${ }^{28}$. Therefore, this implies that the $\mathrm{Pd}$ is highly dispersed in the framework of $\mathrm{m}-\mathrm{MoO}_{3}-\mathrm{P}_{2} \mathrm{O}_{5} / \mathrm{SiO}_{2}$ via a combination of square planar and distorted octahedral configurations, with an averaged oxidation state between $\mathrm{Pd}^{2+}$ and $\mathrm{Pd}^{3}$ ${ }^{+}$. This is in agreement with recently reported strategy of stabilizing single $\mathrm{Pt}$ atoms on a support interface by adopting a proper coordination $^{22}$. The presence of $\mathrm{m}-\mathrm{MoO}_{3}-\mathrm{P}_{2} \mathrm{O}_{5} / \mathrm{SiO}_{2}$ matrix may offer an ideal interface to stabilize Pd with high dispersion.

The structural change of $\mathrm{Pd} / \mathrm{m}-\mathrm{MoO}_{3}-\mathrm{P}_{2} \mathrm{O}_{5} / \mathrm{SiO}_{2}$ during $\mathrm{H}_{2}$ treatment was also investigated. Interestingly, except for the peak intensity decrease for the Pd-O nearest-neighbor (NN) coordination shells, the two higher shell peaks at distances of 2.5 and 3.5 $\AA$. The Pd K-edge EXAFS Fourier transform of reduced catalyst $\left(\mathrm{Pd} / \mathrm{m}-\mathrm{MoO}_{3}-\mathrm{P}_{2} \mathrm{O}_{5} / \mathrm{SiO}_{2}\right)$ display a dramatic intensity increase and a radial shift to lower $R$ direction, as compared to oxidized catalyst (Fig. 2e); similar phenomenon is shown for the Mo Kedge EXAFS results (Fig. 2b). Meanwhile, complementary wavelet transform (WT) EXAFS analysis ${ }^{29}$ reveals strong WT maxima at about 7.0 and $9.5 \AA^{-1}$, which can be, respectively, associated with the $\mathrm{Pd}-\mathrm{P} / \mathrm{Si}$ and $\mathrm{Pd}-\mathrm{Pd} / \mathrm{Mo}$ scatterings (see Supplementary Fig. 6), at a distance of around $2.55 \AA$ surrounding Pd atoms in reduced catalyst, in marked contrast to the WT maxima distribution in oxidized catalyst (Fig. 2f); slight change is observed for the Mo K-edge WT (Fig. 2c). Those results suggest that more oxygen vacancies are produced by $\mathrm{H}_{2}$ reduction in the oxide network of reduced catalyst, which may cause the collapse of the $\mathrm{PdO}_{6}$ octahedra by breaking the bridging oxygen atoms with the neighbor polyhedrons. A least-squares curve-fitting analysis was carried out for the multiple coordination shells of Mo and Pd (Supplementary Figs. 7-10 and Supplementary Tables 2 and 3). The coordination numbers of the $\mathrm{Pd}-\mathrm{O}$ bonding in the first $\mathrm{NN}$ coordination sphere for reduced catalyst (oxidized catalyst) is estimated to be 4.9 (5.6) at a distance of 2.02 (2.03) $\AA$, evidencing the transformation of the $\mathrm{Pd}-\mathrm{O}$ bonding from a distorted octahedral to a square planer coordination. Simultaneously, the number of $\mathrm{Pd} / \mathrm{Mo}$ atoms in the second $\mathrm{NN}$ coordination sphere of $\mathrm{Pd}$ in the reduced catalyst is estimated to be 1.5 at a distance of $2.80 \AA$, much larger than that of 0.4 in the oxidized catalyst, strongly signaling the presence of $\mathrm{Pd}-\mathrm{Pd} /$ Mo atoms. By EXAFS analysis it is difficult to distinguish Mo from Pd; the data suggest a probability of both $\mathrm{Pd}-\mathrm{Mo}$ and Pd-Pd neighbors after reduction, as schematically shown in Fig. $2 \mathrm{~h}$ using density functional theory (DFT) calculations. The data do allow us to conclude there is an absence of large Pd particles, implying a high dispersion for the Pd atoms (further discussions are shown in Supplementary Note 1 and Supplementary Figs. 1113). Thus, XAFS data indicate that there are significant oxygen vacancy sites present in close vicinity of Mo and highly dispersed $\mathrm{Pd}$ in $\mathrm{Pd} / \mathrm{m}-\mathrm{MoO}_{3}-\mathrm{P}_{2} \mathrm{O}_{5} / \mathrm{SiO}_{2}$.

Studies of the activity and stability of the catalyst. Phenol HDO in a batch reactor was initially chosen as a model reaction to evaluate the catalytic activity of $\mathrm{Pd} / \mathrm{m}-\mathrm{MoO}_{3}-\mathrm{P}_{2} \mathrm{O}_{5} / \mathrm{SiO}_{2}$. The total mass of Pd was kept constant in order to benchmark other catalyst systems (Supplementary Table 1). The reaction process using $\mathrm{Pd} / \mathrm{m}-\mathrm{MoO}_{3}-\mathrm{P}_{2} \mathrm{O}_{5} / \mathrm{SiO}_{2}$ catalyst (Fig. 3a and Supplementary Fig. 14) shows an increase in cyclohexane selectivity and a decrease in cyclohexanol selectivity. In comparison, $\mathrm{Pd} / \mathrm{SiO}_{2}$ catalyst only delivered hydrogenated products (cyclohexanone and cyclohexanol) and subsequent dehydration was not observed (Supplementary Fig. 14). These results suggest that in the case of $\mathrm{Pd} / \mathrm{m}-\mathrm{MoO}_{3}-\mathrm{P}_{2} \mathrm{O}_{5} / \mathrm{SiO}_{2}$ catalyst, phenol is initially hydrogenated to cyclohexanol catalyzed by $\mathrm{Pd}$, which is followed by dehydration of cyclohexanol catalyzed by $\mathrm{m}-\mathrm{MoO}_{3}-\mathrm{P}_{2} \mathrm{O}_{5}$ and further hydrogenation of cyclohexene to yield cyclohexane catalyzed by Pd. Via a comparison of product selectivity at near identical conversion level (Fig. 3b), the $\mathrm{Pd} / \mathrm{m}-\mathrm{MoO}_{3}-\mathrm{P}_{2} \mathrm{O}_{5} / \mathrm{SiO}_{2}$ catalyst exhibited a much higher cyclohexane selectivity $(81 \%)$ compared with catalysts without $\mathrm{m}-\mathrm{MoO}_{3}-\mathrm{P}_{2} \mathrm{O}_{5}$, indicating its high dehydration ability is due to the presence of $\mathrm{m}-\mathrm{MoO}_{3}-\mathrm{P}_{2} \mathrm{O}_{5}$. We have compared the performance of $\mathrm{Pd} / \mathrm{m}-\mathrm{MoO}_{3}-\mathrm{P}_{2} \mathrm{O}_{5} / \mathrm{SiO}_{2}$ for the $\mathrm{HDO}$ of phenol to a series of state-of-art bifunctional metal-acid catalysts (Supplementary Table 4). Overall $\mathrm{Pd} / \mathrm{m}-\mathrm{MoO}_{3}-\mathrm{P}_{2} \mathrm{O}_{5} /$ $\mathrm{SiO}_{2}$ demonstrates higher phenol conversions, with better cyclohexane selectivity at a lower temperature and lower $\mathrm{H}_{2}$ pressure than any of other catalyst systems. The catalyst was reused and showed no obvious deactivation after five cycles (Fig. 3c), showing its stability under batch reaction conditions. In order to investigate stability under more industrially related conditions, $\mathrm{Pd} / \mathrm{m}-\mathrm{MoO}_{3}-\mathrm{P}_{2} \mathrm{O}_{5} / \mathrm{SiO}_{2}$ was evaluated under continuous flow condition at $433 \mathrm{~K}, 1 \mathrm{MPa} \mathrm{H}_{2}$ with flow rate of 10 $\mathrm{cm}^{3}$ (STP) $\mathrm{min}^{-1}$, weight hour space velocity (WHSV) $=0.18 \mathrm{~h}^{-1}$. The results show that there is some degree of deactivation (phenol conversion from 84.2 to $77.2 \%$ ) but stable cyclohexane selectivity (from 68.2 to $68.8 \%$ ) in the 32-h test (Fig. 3d), exhibiting higher cyclohexanol selectivity and stability than those in recent report under similar conditions (cyclohexane yield decrease from 52 to $28 \%$ in $4 \mathrm{~h})^{17}$. The spent catalyst shows no obvious change (Supplementary Figs. 15, 16). The Mo and Pd K-edge XANES and 
a

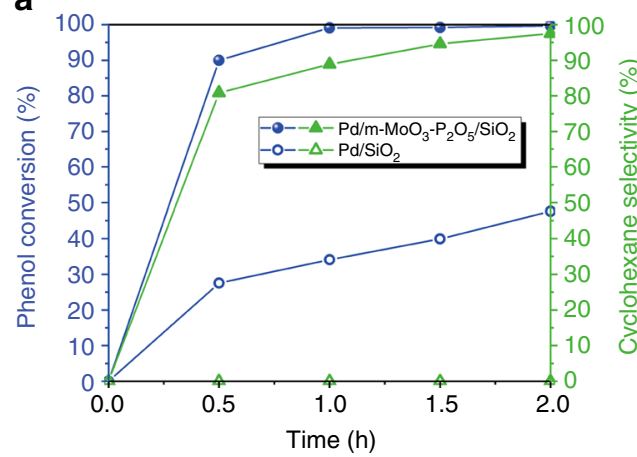

C

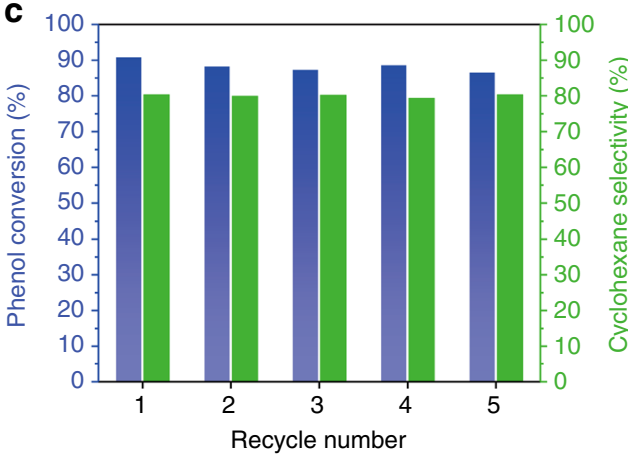

b

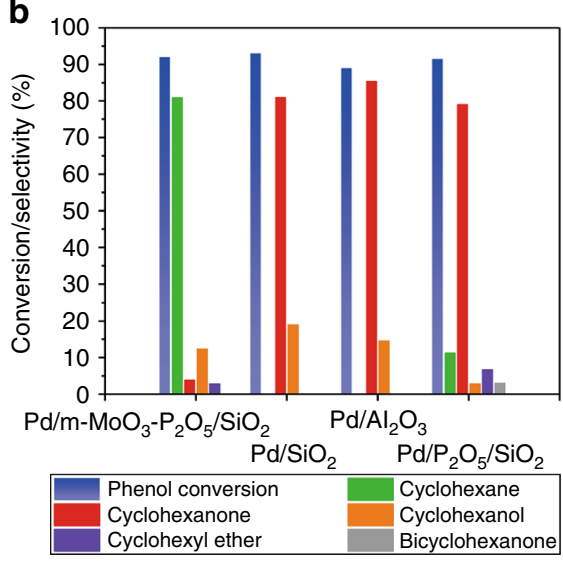

d 100

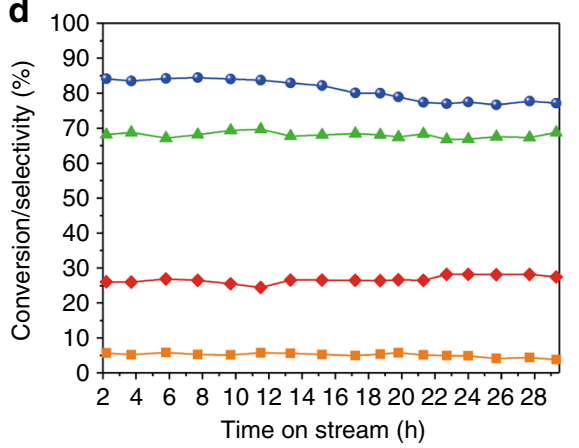

$\because$ Phenol conversion $\rightarrow$ Cyclohexane

Fig. 3 Catalytic performance on $\mathrm{HDO}$ of phenol. a Time dependence of the phenol conversion and cyclohexanol selectivity using $\mathrm{Pd} / \mathrm{m}-\mathrm{MoO}_{3}-\mathrm{P}_{2} \mathrm{O}_{5} / \mathrm{SiO}_{2}$ and $\mathrm{Pd} / \mathrm{SiO}_{2}$ catalysts in batch reactions. Reaction conditions: phenol $(0.195 \mathrm{mmol})$, catalyst (including $\left.0.00045 \mathrm{mmol} \mathrm{Pd}\right), \mathrm{decalin}(7 \mathrm{~mL}), 383 \mathrm{~K}, 1 \mathrm{MPa}$ $\mathrm{H}_{2}$; reaction mixture stirred at $800 \mathrm{rpm}$. b Comparison of product selectivity of different catalysts at identical conversion level at $383 \mathrm{~K}, 1 \mathrm{Mpa} \mathrm{H}_{2}$ in batch reaction. Reaction conditions: phenol $(0.195 \mathrm{mmol}$ ), catalyst (including $0.00045 \mathrm{mmol} \mathrm{Pd})$, decalin $(7 \mathrm{~mL})$, reaction mixture stirred at $800 \mathrm{rpm}$. c Stability test of $\mathrm{Pd} / \mathrm{m}-\mathrm{MoO}_{3}-\mathrm{P}_{2} \mathrm{O}_{5} / \mathrm{SiO}_{2}$ in batch reaction. Reaction conditions: $383 \mathrm{~K}, 1 \mathrm{Mpa} \mathrm{H}_{2}, 0.5 \mathrm{~h}$. $\mathbf{d}$ Long-term stability test on the $\mathrm{Pd} / \mathrm{m}-\mathrm{MoO}_{3}-\mathrm{P}_{2} \mathrm{O}_{5} / \mathrm{SiO} \mathrm{O}_{2}$ at $433 \mathrm{~K}, 1 \mathrm{MPa} \mathrm{H}_{2}$ with a weight hourly space velocity of $0.17 \mathrm{~h}^{-1}$ in a continuous flow reaction

EXAFS spectra are also given for the spent catalyst, exhibiting no obvious changes in the local structure around Mo and Pd atoms (Supplementary Fig. 17). The deactivation was mainly due to carbonaceous deposition (Supplementary Fig. 18). To evaluate reuse ability, $\mathrm{Pd} / \mathrm{m}-\mathrm{MoO}_{3}-\mathrm{P}_{2} \mathrm{O}_{5} / \mathrm{SiO}_{2}$ was evaluated under continuous flow conditions $\left(453 \mathrm{~K}, 1 \mathrm{MPa} \mathrm{H}_{2}\right.$ with WHSV of $0.085 \mathrm{~h}^{-1}$ ). As shown in Supplementary Fig. 19, after it was deactivated (phenol conversion from $>99$ to $69.0 \%$, cyclohexanol selectivity from 98.3 to $90.4 \%$ ) in $135 \mathrm{~h}$, the spent catalyst was calcined at $673 \mathrm{~K}$ for $5 \mathrm{~h}$ to remove the carbonaceous deposition and re-used for another two runs. The result shows that the initial performance could be substantially recovered, with phenol conversion of $>99 \%$ ( 1 st run), $94.5 \%$ (2nd run), and $94.0 \%$ ( 3 rd run), respectively, and cyclohexane selectivity of $98.3 \%$ (1st run), $98.4 \%$ (2nd run), and $96.7 \%$ (3rd run), respectively, and a similar deactivation trend was observed. This good re-usability ensures a long-term reaction efficiency (maintaining phenol conversion $>60 \%$ and cyclohexane selectivity $>90 \%$ ) in three runs for over $419 \mathrm{~h}$ without obvious catalyst leaching (Supplementary Table 1).

Studies of the effects of Brønsted and Lewis acidity on reaction. ${ }^{31}$ P MAS NMR spectrum were recorded following adsorption of the trimethylphosphine oxide (TMPO) probe molecule, giving information about the acid type (Brønsted vs. Lewis), strength and concentration in the materials ${ }^{30}$. The ${ }^{31} \mathrm{P}$ MAS NMR spectrum (Fig. 4a) of the TMPO-adsorbed on reduced catalyst $(\mathrm{Pd} /$ $\mathrm{m}-\mathrm{MoO}_{3}-\mathrm{P}_{2} \mathrm{O}_{5} / \mathrm{SiO}_{2}$ ) exhibits two distinct resonances at 58.0 and $73 \mathrm{ppm}$, both signals are attributed to the protonation of TMPO by surface Brønsted acid sites with exceptionally high density reaching $0.0138 \mathrm{mmol} / \mathrm{m}^{2}$ (Supplementary Table 5 and Supplementary Fig. 20), which is 2.6-fold higher than a strong acidic zeolite HZSM-5 ( $\mathrm{Si}$ to $\mathrm{Al}$ of 15$)^{31}$. The reduced catalyst exhibits another new resonance at $45 \mathrm{ppm}$, which was not observed in oxidized catalyst and could be attributed to Lewis acid with density of $0.0075 \mathrm{mmol} / \mathrm{m}^{2}$. A series of catalysts with different Brønsted acid sites and Lewis acid sites were prepared by the same procedure as the $\mathrm{Pd} / \mathrm{m}-\mathrm{MoO}_{3}-\mathrm{P}_{2} \mathrm{O}_{5} / \mathrm{SiO}_{2}$ catalyst by varying the molar ratio of P:Mo (Supplementary Table 5). The existence of the Lewis acid site is observed only on catalysts containing Mo species, thus it is most likely linked to oxygen vacancy associated with Mo centers ${ }^{32}$, which is well consistent with abovementioned XAFS analysis. The formation of oxygen vacancy is observed by temperature programmed reduction (TPR, Supplementary Fig. 21), and could be linked with the reduction of surface oxidation state evidenced by multi-frequency electron paramagnetic resonance (EPR, see Methods, Supplementary Figs. 22-24) and by solid-state magnetic susceptibility measurements (Supplementary Fig. 25).

We believe that the excellent performance of $\mathrm{Pd} /$ $\mathrm{m}-\mathrm{MoO}_{3}-\mathrm{P}_{2} \mathrm{O}_{5} / \mathrm{SiO}_{2}$ for $\mathrm{HDO}$ may be attributed to cooperative effects between highly dispersed Pd, strong Brønsted acid sites, and Lewis acid sites. The highly dispersed Pd allows for higher hydrogenation activity (Fig. 3a) and enhanced metal atom efficiency compared with $\mathrm{Pd} / \mathrm{SiO}_{2}$ (Supplementary Fig. 14), by 
a

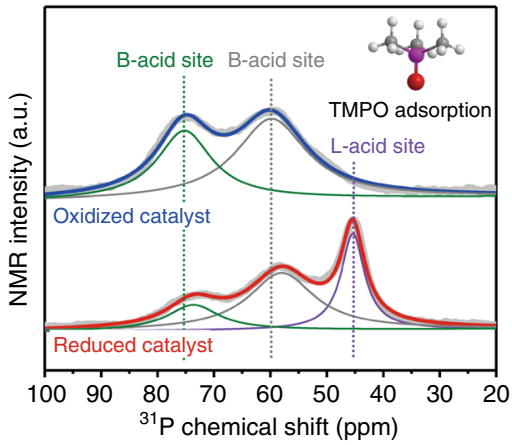

b

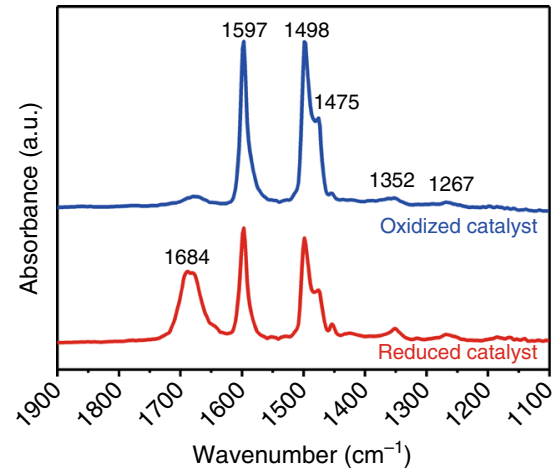

Fig. 4 Surface analyses of $\mathrm{Pd} / \mathrm{m}-\mathrm{MoO}_{3}-\mathrm{P}_{2} \mathrm{O}_{5} / \mathrm{SiO}_{2}$ catalyst. a Solid-state ${ }^{31} \mathrm{P} \mathrm{MAS}$ NMR spectra of TMPO-adsorbed on the oxidized catalyst and reduced catalyst ( $\left.\mathrm{Pd} / \mathrm{m}-\mathrm{MoO}_{3}-\mathrm{P}_{2} \mathrm{O}_{5} / \mathrm{SiO}_{2}\right)$. Inset displayed TMPO molecule. b DRIFTS spectra at $1100-1900 \mathrm{~cm}^{-1}$ obtained over oxidized catalyst and reduced catalyst $\left(\mathrm{Pd} / \mathrm{m}-\mathrm{MoO}_{3}-\mathrm{P}_{2} \mathrm{O}_{5} / \mathrm{SiO}_{2}\right)$ in a reaction mixture containing phenol and $\mathrm{He}$ at $383 \mathrm{~K}$
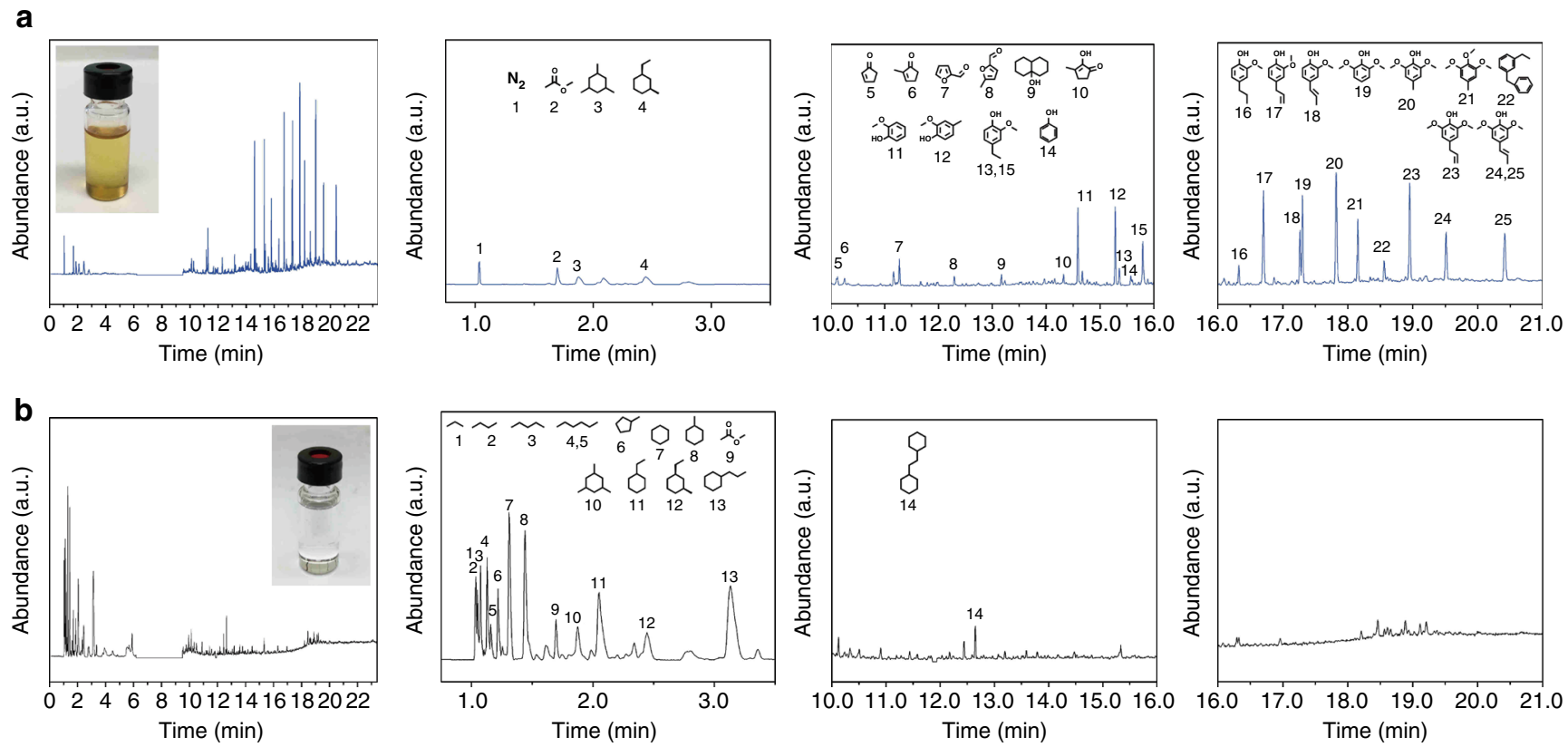

Fig. 5 GC-MS analysis before and after upgrading. a GC-MS analysis of WIBO dissolved in decalin before upgrading. $\mathbf{b}$ GC-MS analysis of upgrading product after a batch reaction. Reaction conditions: WIBO $(86.2 \mathrm{mg}), \mathrm{Pd} / \mathrm{m}-\mathrm{MoO}_{3}-\mathrm{P}_{2} \mathrm{O}_{5} / \mathrm{SiO}_{2}(170.8 \mathrm{mg})$, decalin $(7 \mathrm{~mL}), 453 \mathrm{~K}, 1 \mathrm{MPa} \mathrm{H}, 4 \mathrm{~h}$, stirred at $800 \mathrm{rpm}$. MS detector was off from 6.2 to $9.5 \mathrm{~min}$, and 11.8 to $11.9 \mathrm{~min}$ to block decalin and tetralin signals. The overall GC-MS patterns and three enlarged regions are shown. Insets show the images of mixtures before and after upgrading, respectively

increasing the number of exposed surface atoms by using very low Pd loading amount of $0.48 \mathrm{wt} \%$. The catalysts with different Brønsted acid sites (Supplementary Table 5) were compared in the dehydration of cyclohexanol (Supplementary Table 6), which is the most important intermediate in the HDO of phenol. Since most of the samples show comparable Brønsted acid strength, respectively, revealed by resonance position of ${ }^{31} \mathrm{P}$ MAS NMR spectrum (except $\mathrm{Pd} / \mathrm{P}_{2} \mathrm{O}_{5} / \mathrm{SiO}_{2} \quad(\mathrm{P}: \mathrm{Mo}=1: 0)$ which shows weaker Brønsted acid strength), one can look into the correlation between Brønsted acid and dehydration activity. The result shows that only samples containing Brønsted acid sites have activity, suggesting the dehydration is a Brønsted acid-catalyzed process. Specifically, $\mathrm{Pd} / \mathrm{m}-\mathrm{MoO}_{3}-\mathrm{P}_{2} \mathrm{O}_{5} / \mathrm{SiO}_{2}(\mathrm{P}: \mathrm{Mo}=1: 1$, the reduced catalyst shown in the main work) with the most Brønsted acid sites is a more active dehydration catalyst, and also $\mathrm{Pd} /$ $\mathrm{m}-\mathrm{MoO}_{3}-\mathrm{P}_{2} \mathrm{O}_{5} / \mathrm{SiO}_{2}(\mathrm{P}: \mathrm{Mo}=2: 1)$ with higher Brønsted acid sites compared with $\mathrm{Pd} / \mathrm{MoO}_{3} / \mathrm{SiO}_{2}(\mathrm{P}: \mathrm{Mo}=0: 1)$ has higher dehydration activity (conversion: 25.2 vs. $19.8 \%$ ), which are consistent with the correlation between the Brønsted acid sites and the dehydration activity ${ }^{16}, 23$. It is also observed that $\mathrm{Pd} /$ $\mathrm{P}_{2} \mathrm{O}_{5} / \mathrm{SiO}_{2}$ has lower dehydration activity compared with $\mathrm{Pd} /$ $\mathrm{MoO}_{3} / \mathrm{SiO}_{2}$ (12.8 vs. $19.8 \%$ ), although its Brønsted acid sites is higher. This could be due to its relatively weaker Brønsted acid strength ${ }^{13}$. The role of Lewis acid site on phenol conversion was further studied by performing diffuse-reflectance infrared Fourier transform spectroscopy (DRIFTS) upon exposure of the oxidized and reduced catalyst $\left(\mathrm{Pd} / \mathrm{m}-\mathrm{MoO}_{3}-\mathrm{P}_{2} \mathrm{O}_{5} / \mathrm{SiO}_{2}\right)$ to a phenol/He mixture at reaction temperature $(383 \mathrm{~K})$. In the measurements, the reduced catalyst was first treated with $5 \% \mathrm{H}_{2} / \mathrm{Ar}$ at $383 \mathrm{~K}$ before exposed to phenol/He mixture. The DRIFTS spectra of both reduced catalyst and oxidized catalyst (Fig. 4b) show bands at 1597, 1497, 1475, 1352 and $1267 \mathrm{~cm}^{-1}$, which correspond to different vibrational modes of phenoxy species ${ }^{33}$. Compared with oxidized catalyst, the reduced catalyst shows more pronounced bands at 1684, 2951 and $2874 \mathrm{~cm}^{-1}$ (Fig. 4b, Supplementary Fig. 26), which could be assigned to the $v(\mathrm{C}=\mathrm{O})$ and $v(\mathrm{C}-\mathrm{H})$ 


\section{Table $1 \mathrm{HDO}$ of water-insoluble wood and bark-derived} WIBO over $\mathrm{Pd} / \mathrm{m}-\mathrm{MoO}_{3}-\mathrm{P}_{2} \mathrm{O}_{5} / \mathrm{SiO}_{2}$ catalyst

\begin{tabular}{|c|c|c|}
\hline \multirow[t]{2}{*}{ Products } & \multicolumn{2}{|c|}{ Mass yield ${ }^{a} /$ carbon yield $^{b}$ (wt\%/wt\%) } \\
\hline & Entry $1^{c}$ & Entry $2^{d}$ \\
\hline Pentane & $0.9 / 1.5$ & $7.4 / 11.4$ \\
\hline Hexane & $1.2 / 1.8$ & $5.1 / 7.9$ \\
\hline Methylcyclopentane & $0.9 / 1.4$ & $3.7 / 5.8$ \\
\hline Cyclohexanes & $5.6 / 10.2$ & $13.4 / 21.2$ \\
\hline Total liquid alkanes & $9.4 / 14.8$ & $29.6 / 46.3$ \\
\hline Others ${ }^{\mathrm{e}}$ & $1.2 / 2.2$ & $6.8 / 10.2$ \\
\hline
\end{tabular}

aOn the basis of the mass of moisture-free WIBO

On the basis of the mass of carbon in WIBO

${ }^{C}$ Reaction condition: WIBO $(86.2 \mathrm{mg}), \mathrm{Pd} / \mathrm{m}-\mathrm{MoO}_{3}-\mathrm{P}_{2} \mathrm{O}_{5} / \mathrm{SiO}_{2}(170.83 \mathrm{mg})$, decalin $(7 \mathrm{~mL}$ ), $453 \mathrm{~K}, 1 \mathrm{MPa} \mathrm{H}$, $4 \mathrm{~h}$, stirred at $800 \mathrm{rpm}$

${ }^{\mathrm{d}}$ Reaction condition: WIBO (87.2 mg), $\mathrm{Pd} / \mathrm{MoO}_{3}-\mathrm{P}_{2} \mathrm{O}_{5} / \mathrm{SiO}_{2}(170.8 \mathrm{mg})$, decalin $(7 \mathrm{~mL}), 523 \mathrm{~K}$, $1 \mathrm{MPa} \mathrm{H}_{2}, 15 \mathrm{~h}$, stirred at $800 \mathrm{rpm}$

e Others mainly include $\mathrm{C}_{3}-\mathrm{C}_{4}$ alkanes

stretching modes, respectively, of adsorbed 2,4-cyclohexadien-1one tautomer of phenol ${ }^{33}, 34$. Considering that both the DRIFTS of spectra of oxidized $\mathrm{Pd} / \mathrm{SiO}_{2}$ and reduced $\mathrm{Pd} / \mathrm{SiO}_{2}$ do not show obvious bands for 2,4-cyclohexadien-1-one (Supplementary Fig. 27), the formation of this compound is more likely promoted by Lewis acid sites (oxygen vacancy associated with Mo centers) on reduced catalyst via tautomerization of phenol. This compound is an important intermediate in the HDO of phenol supported by Priscillat et al. studies ${ }^{33}$, which could be first hydrogenated to 2-cyclohexen-1-one, then to cyclohexanone and further to cyclohexanol.

HDO of WIBO. Based on the above understanding, efficiency test using $\mathrm{Pd} / \mathrm{m}-\mathrm{MoO}_{3}-\mathrm{P}_{2} \mathrm{O}_{5} / \mathrm{SiO}_{2}$ for upgrading a WIBO derived from fast pyrolysis of grounded eucalyptus wood chip and bark were carried out. This WIBO sample was a dark red, treacle-like, viscous liquid (Supplementary Fig. 28) with a $47.2 \mathrm{wt} \%$ carbon content and a $42.8 \mathrm{wt} \%$ oxygen content (Supplementary Table 7). The WIBO contains $13 \mathrm{wt} \%$ moisture determined by Karl Fisher method, which mainly derived from the feedstock and also the dehydration reactions during flash pyrolysis treatment ${ }^{35}$. The content of the WIBO was studied using gas chromatograph-mass spectrometry (GC-MS) (Fig. 5a and Supplementary Fig. 29). The results show the WIBO contains a series of oxygenated monomers involving phenolic compounds such as guaiacol, syringol, and furans (4.7 wt\% of total WIBO mass). High-performance liquid chromatography (HPLC) of the water extract of the WIBO (Supplementary Fig. 30) showed no sugar-type monomers before it was hydrolyzed. The remaining mass can be attributed to lignin and sugar oligomers that are undetectable in both GC-MS and HPLC. Gel permeation chromatography (GPC) analysis (Supplementary Fig. 31) verified the presence of oligomers in the WIBO with molecular weight up to $1000 \mathrm{Da}$ and weight average molecular weight $\left(M_{\mathrm{w}}\right)$ of 401 . This $M_{\mathrm{w}}$ value is consistent with those reported for wood pyrolysis oils $^{36}$.

HDO of this WIBO was carried out in a batch reactor at $453 \mathrm{~K}$ and $1 \mathrm{MPa} \mathrm{H}_{2}$ in the presence of $\mathrm{Pd} / \mathrm{m}-\mathrm{MoO}_{3}-\mathrm{P}_{2} \mathrm{O}_{5} / \mathrm{SiO}_{2}$ catalyst. Total conversion of the oxygenated monomers was achieved after $4 \mathrm{~h}$ (Fig. 5b), with the production of $9.4 \mathrm{wt} \%$ total mass yield of liquid alkanes involving $0.9 \mathrm{wt} \%$ pentane, $1.2 \mathrm{wt} \%$ hexane, and $5.6 \mathrm{wt} \% \mathrm{C}_{6}-\mathrm{C}_{9}$ cycloalkanes (cyclohexane, methylcyclohexane, ethylcyclohexane, and propylcyclohexane; see Table 1 and Supplementary Fig. 32). Overall a 10.2\% carbon yield in the form of cyclohexanes was obtained. This is higher than the maximum carbon yield (5.7\%) possible from the lignin- derived monomers present in the WIBO. This indicates that some oligomers in the WIBO were converted into cyclohexanes. The production of pentane and hexane suggests that HDO of cellulose and hemicellulose into alkanes are achieved, which is supported by the earlier literature ${ }^{19}$. The color of the mixture became lighter after the reaction, serving as another qualitative indicator of the HDO efficiency (inset in Fig. 5a, b). To further increase the mass yield of liquid alkanes, the reaction was carried out at an increased temperature. At $523 \mathrm{~K}$ and $1 \mathrm{MPa} \mathrm{H}_{2}, 29.6 \mathrm{wt} \%$ total mass yield and $46.3 \%$ total carbon yield of liquid alkanes was achieved after $15 \mathrm{~h}$, the mass yield of cyclohexanes, pentane, and hexane reached 13.4, 7.4 and $5.1 \mathrm{wt} \%$, respectively (see Methods, Table 1, Supplementary Fig. 33). It should be noted that the total carbon yield is comparable to the state-of-art in catalytic performance ${ }^{19,} 37,38$. GPC analysis (Supplementary Fig. 34) shows the decrease of oligomers. Although reaction mechanisms for HDO of different classes of oxygenates in bio-oil could be different, these results clearly indicate that the catalyst has a high performance for simultaneous $\mathrm{HDO}$ of lignin, cellulose, and hemicellulose-derived oligomers into liquid alkanes.

\section{Discussion}

We report a highly active HDO catalyst comprising highly dispersed $\mathrm{Pd}$ and ultrafine Mo phosphate nanoparticles supported on $\mathrm{SiO}_{2}$. This catalyst is $100 \%$ effective and is $97.5 \%$ selective for HDO of phenol to cyclohexane under mild conditions, showing regeneration ability in long-term continuous flow tests for $419 \mathrm{~h}$ with some decrease in catalytic performance after $32 \mathrm{~h}$ in a continuous flow reaction. There are cooperative effects between highly dispersed $\mathrm{Pd}$, Brønsted and Lewis acid sites on $\mathrm{Pd} /$ $\mathrm{m}-\mathrm{MoO}_{3}-\mathrm{P}_{2} \mathrm{O}_{5} / \mathrm{SiO}_{2}$, which shows to be important for the efficient catalytic HDO behavior. Using water-insoluble fraction of wood and bark-derived WIBO, the catalyst showed state-of-art performance for the simultaneous HDO of lignin, cellulose, and hemicellulose-derived oligomers into liquid alkanes with total mass yield of $29.6 \mathrm{wt} \%$ under mild condition $\left(523 \mathrm{~K}, 1 \mathrm{MPa} \mathrm{H}_{2}\right)$. Further work will include mechanistic investigations for HDOs of different classes of oxygenates in bio-oil to fully understand the high efficiency of this catalyst.

\section{Methods}

Sample preparation. $\mathrm{Pd} / \mathrm{m}-\mathrm{MoO}_{3}-\mathrm{P}_{2} \mathrm{O}_{5} / \mathrm{SiO}_{2}$ synthesis: $\left(\mathrm{NH}_{4}\right)_{6} \mathrm{Mo}_{7} \mathrm{O}_{24} \bullet 4 \mathrm{H}_{2} \mathrm{O}$ $(0.021 \mathrm{mmol}),\left(\mathrm{NH}_{4}\right)_{2} \mathrm{HPO}_{4}(0.150 \mathrm{mmol})$, citric acid $(0.30 \mathrm{mmol})$ were dissolved in $0.3 \mathrm{~mL}$ of $\mathrm{HCl}$ aqueous solution containing $\mathrm{PdCl}_{2}(1.5 \mathrm{mg})$. The mixture was stirred for $1 \mathrm{~h}$ and then added dropwise to $\mathrm{SiO}_{2}(0.12 \mathrm{~g})$. The obtained glue-like sample was dried in an oven at $397 \mathrm{~K}$ overnight and calcined at $773 \mathrm{~K}$ in a muffle furnace for $5 \mathrm{~h}$ at a rising rate of $5 \mathrm{~K} / \mathrm{min}$. The calcined sample, named as $\mathrm{Pd} /$ $\mathrm{MoO}_{3}-\mathrm{P}_{2} \mathrm{O}_{5} / \mathrm{SiO}_{2}$, was reduced in $\mathrm{H}_{2}$ at $323 \mathrm{~K}$ for $3 \mathrm{~h}$ with a flowing rate of 75 $\mathrm{cm}^{3} / \mathrm{min}$. The calcined sample changed to a greenish-blue color following reduction. This reduced sample was named $\mathrm{Pd} / \mathrm{m}-\mathrm{MoO}_{3}-\mathrm{P}_{2} \mathrm{O}_{5} / \mathrm{SiO}_{2}$. The synthesis of $\mathrm{Pd} / \mathrm{P}_{2} \mathrm{O}_{5} / \mathrm{SiO}_{2}$ was similar as for $\mathrm{Pd} / \mathrm{m}-\mathrm{MoO}_{3}-\mathrm{P}_{2} \mathrm{O}_{5} / \mathrm{SiO}_{2}$, except with no addition of $\left(\mathrm{NH}_{4}\right)_{6} \mathrm{Mo}_{7} \mathrm{O}_{24} \bullet 4 \mathrm{H}_{2} \mathrm{O} . \mathrm{Pd} / \mathrm{SiO}_{2}$ was prepared by dropwise addition of $0.3 \mathrm{~mL}$ of prepared $\mathrm{PdCl}_{2}$ solution into $\mathrm{SiO}_{2}$ under strong stirring. The following operations are the same as the one for $\mathrm{Pd} / \mathrm{m}-\mathrm{MoO}_{3}-\mathrm{P}_{2} \mathrm{O}_{5} / \mathrm{SiO}_{2}$. The fresh catalyst was protected in $\mathrm{N}_{2}$ and quickly prepared as samples for further characterizations and catalytic tests.

High-resolution TEM. HRTEM images were acquired with JEOL JEM-2100F fieldemission TEM with an accelerating voltage of $200 \mathrm{kV}$.

Aberration-corrected TEM. Aberration-corrected TEM was performed on JEOL $200 \mathrm{~F}$ TEM operated at $200 \mathrm{keV}$. The attainable spatial resolution of the microscope is $78 \mathrm{pm}$ with a probe spherical-aberration corrector. Both $\mathrm{ABF}$ and HAADF were obtained with the illumination semi-angle of $25 \mathrm{mrad}$ and probe current of $100 \mathrm{pA}$. The dwell time for imaging was set at $10 \mathrm{~ms}$ per pixel to ensure desirable signal to noise ratio. The collection angles for the $\mathrm{ABF}$ and $\mathrm{HAADF}$ images were fixed at 12-25 and 90-250 mrad, respectively. EDXS was performed to locate elemental distribution of Mo, P, and Pd with an SDD-type EDX detector. The attainable energy-resolution of the EDX detector is $130 \mathrm{eV}$. A higher beam current of $300 \mathrm{pA}$ was used with a longer dwell time of $0.1 \mathrm{~ms}$ per pixel repeated for 200 times. Spatial 
drift was corrected with a simultaneous image collector. Mo L-edge, P K-edge and Pd L-edge were used for elemental mapping.

Power X-ray diffraction. PXRD data were obtained on a PANAnalytical X'Pert Pro diffractometer in reflection mode at $40 \mathrm{kV}$ and $40 \mathrm{~mA}$ using $\mathrm{Cu}$ K $\alpha$ radiation.

Raman spectroscopy. Raman spectra were recorded on a Renishaw Raman spectrometer at a laser excitation wavelength of $633 \mathrm{~nm}$.

X-ray absorption data collection and analysis. Mo K-edge and Pd K-edge X-ray absorption spectra were acquired under ambient condition at beamline BL14W1 of Shanghai Synchrotron Radiation Facility (SSRF) using a Si(311) double-crystal monochromator in transmission and fluorescence modes, respectively. The storage ring of SSRF was operated at $3.5 \mathrm{GeV}$ with a maximum current of $250 \mathrm{~mA}$. The energy was calibrated using $\mathrm{Mo} / \mathrm{Pd}$ foil. While the incident and transmitted $\mathrm{X}$-ray intensities were monitored by using standard ion chambers, the fluorescence signal was detected by using a 7 element Ge detector. To prevent air oxidation, the samples were prepared in a glove box, and they were uniformly mixed with BN powder and pressed to a pellet, which was sealed in a cell holder with Kapton windows for XAFS measurement. The XAFS raw data were background-subtracted, normalized, and Fourier transformed by the standard procedures with the ATHENA program ${ }^{39}, 40$. Least-squares curve-fitting analysis of the EXAFS $\chi(k)$ data was carried out using the ARTEMIS program ${ }^{39}$ with the theoretical scattering amplitudes, phase shifts, and the photoelectron mean-free path for all paths calculated by ab-initio code FEFF9.05 ${ }^{41}$. The details of curve fitting are discussed in Supplementary Figs. 7-10 and Supplementary Tables 2 and 3. The Pd K-edge theoretical XANES calculations were carried out with the FDMNES code in the framework of real-space full multiple-scattering scheme using Muffin-tin approximation for the potential ${ }^{41-43}$. The energy-dependent exchange-correlation potential was calculated in the real Hedin-Lundqvist scheme, and then the spectra are convoluted using a Lorentzian function with an energy-dependent width to account for the broadening due both to the core-hole width and to the final state width. Satisfactory convergence for cluster sizes had been achieved.

Density functional theory calculations. The electronic structure calculations were performed using the density functional theory and a plane-wave basis set as implemented in the VASP code ${ }^{44}$. The electron-ion interaction was treated by the projector-augmented wave method ${ }^{45}$ with the outmost $s, p$, and $d$ states as valence orbital. The electron exchange-correlation energy was described by the modified Perdew-Burke-Ernzerhof generalized gradient approximation for solids (PBEsol $)^{46}$. The kinetic energy cutoff was set to $350 \mathrm{eV}$, and the Brillouin zone was sampled in Monkhorst-Pack $k$ point meshes with an interpolation grid spacing of $0.04 \AA^{-1}$ for the 240 atoms supercell, to achieve the total energy convergence of less than 0.001 $\mathrm{eV} /$ atom. Structural relaxation was allowed until the force on each atom was $<0.01$ $\mathrm{eV} / \AA$.

Catalysis testing in batch reactions. Phenol $(18.4 \mathrm{mg}, 0.195 \mathrm{mmol})$ was added into a stainless steel Parr autoclave (reactor volume, $50 \mathrm{~mL}$ ) with decalin $(7 \mathrm{~mL})$, together with $\mathrm{Pd} / \mathrm{m}-\mathrm{MoO}_{3}-\mathrm{P}_{2} \mathrm{O}_{5} / \mathrm{SiO}_{2}(10.0 \mathrm{mg})$ and was stirred for $10 \mathrm{~min}$. The autoclave was then sealed, purged with $\mathrm{H}_{2}$ for three times, and then placed under 1 $\mathrm{MPa} \mathrm{H}_{2}$ at room temperature. The reaction was carried out at different temperature for a certain time with a stirring speed of $800 \mathrm{rpm}$. After reaction, the organic product was collected and analyzed by GC-MS. For the re-usability experiments using the $\mathrm{Pd} / \mathrm{m}-\mathrm{MoO}_{3}-\mathrm{P}_{2} \mathrm{O}_{5} / \mathrm{SiO}_{2}$ catalyst; after each reaction cycle, the spent catalyst was separated by centrifugation and used for the next run.

Catalysis testing in fixed bed reactions. The fixed bed reaction was carried out in a HEL made continuous trickle bed reactor (mode FlowCAT) with both the liquid feed and hydrogen gas passing in downward direction. The $\mathrm{Pd} / \mathrm{m}-\mathrm{MoO}_{3}-\mathrm{P}_{2} \mathrm{O}_{5} /$ $\mathrm{SiO}_{2}$ catalyst $(127 \mathrm{mg}$ ) was located in the middle of the tubular reactor with quartz wool plugs on both the sides. Liquid feed was prepared by dissolving phenol in decalin to form a solution of $3.6 \mathrm{mg} / \mathrm{mL}$. The reaction was carried out at $433-453 \mathrm{~K}$ (Fig. 3d and Supplementary Fig. 19), $1 \mathrm{Mpa}$ with $\mathrm{H}_{2}$ flow rate of $10 \mathrm{~cm}^{3}(\mathrm{STP}) \mathrm{min}^{-1}$ and liquid flow rate of $0.05-0.1 \mathrm{~mL} \mathrm{~min}^{-1}$ (Fig. $3 \mathrm{~d}$ and Supplementary Fig. 16). The liquid was preheated at the desired reaction temperature before being fed into the reactor. The products were periodically collected from the outlet stream throughout the reaction and were analyzed by GC-MS. WHSV was calculated by dividing the feed flow rate per hour by weight of catalyst. The spent catalyst ( $32 \mathrm{~h}$ test) was collected and protected in $\mathrm{N}_{2}$, and then quickly prepared as samples for further characterizations. For the re-usability of the $\mathrm{Pd} / \mathrm{m}-\mathrm{MoO}_{3}-\mathrm{P}_{2} \mathrm{O}_{5} / \mathrm{SiO}$ catalyst, the spent catalyst was not removed from the reactor but calcined on-site in air at $673 \mathrm{~K}$ for $5 \mathrm{~h}$ with a flowing rate of $20 \mathrm{~cm}^{3} / \mathrm{min}$ and then reduced in $\mathrm{H}_{2}$ at $323 \mathrm{~K}$ for $3 \mathrm{~h}$ with a flowing rate of $75 \mathrm{~cm}^{3} / \mathrm{min}$.

GC-MS analysis. GC-MS analysis was conducted by using an Agilent gas chromatograph equipped with an Agilent 19091 N-133 column of mode HP-INNOWax with high polarity, $30 \mathrm{~m} \times 250 \mu \mathrm{m} \times 0.25 \mu \mathrm{m}$ connected online to mass spectrometer. The GC oven was programmed as: hold at initial temperature of $313 \mathrm{~K}$ for 5 min, ramp at $15 \mathrm{~K} \mathrm{~min}^{-1}$ to $523 \mathrm{~K}$ and hold at $523 \mathrm{~K}$ for $5 \mathrm{~min}$. 2-isopropylphenol was used as the internal standard. The peaks were analyzed by comparing the corresponding spectra with those of the NIST 2011 MS library.

WIBO analysis and conversion. The WIBO was derived from fast pyrolysis of grounded eucalyptus wood chip and bark. Wood log (wood chip + bark) was fed directly into pyrolysis reactor in forms of grounded wood and bark. Pyrolysis was carried out at $773 \mathrm{~K}$ in absence of oxygen. The produced bio-oil was separated into water-soluble phase and water-insoluble phase. For the WIBO part, the volatile species, mainly lignin-derived monomers, were determined by dissolving $84.0 \mathrm{mg}$ WIBO and $4.03 \mathrm{mg}$ internal standard, 2-isopropylphenol, in $1.5 \mathrm{~mL}$ methanol or only WIBO in decalin, and analyzing by GC-MS, as presented in Supplementary Fig. 29 and Fig. 5a. For the analysis of sugar component, $1.038 \mathrm{~g}$ WIBO was washed with $30 \mathrm{~mL}$ water while stirring at room temperature for $12 \mathrm{~h}$, and the resulting water extraction was analyzed by HPLC, as presented in Supplementary Fig. 30. HPLC analysis was conducted by using a Laserchrom HPLC system equipped with a Aminex HPX $87 \mathrm{H} 300 \times 7.8$ column and Refractive Index Detector at $308 \mathrm{~K}$ using $0.025 \mathrm{M} \mathrm{H}_{2} \mathrm{SO}_{4}$ as the mobile phase with flow rate of $0.6 \mathrm{~mL} \mathrm{~min}^{-1}$. To hydrolyze oligomers into monomeric sugars, $200 \mu \mathrm{L}$ concentrated $\mathrm{H}_{2} \mathrm{SO}_{4}$ was added into 2 $\mathrm{mL}$ upper water solution and heated at $393 \mathrm{~K}$ for $1 \mathrm{~h}$. The resultant was also analyzed by HPLC, as presented in Supplementary Fig. 30.

For reaction at $453 \mathrm{~K}$, WIBO $(86.2 \mathrm{mg})$, decalin $(7 \mathrm{~mL})$, and $\mathrm{Pd} /$ $\mathrm{m}-\mathrm{MoO}_{3}-\mathrm{P}_{2} \mathrm{O}_{5} / \mathrm{SiO}_{2}(170.8 \mathrm{mg})$ were added into a stainless steel Parr autoclave (reactor volume of $50 \mathrm{~mL}$ ) and stirred for $10 \mathrm{~min}$. Then, the autoclave was sealed, purged three times with $\mathrm{H}_{2}$, and placed under $1 \mathrm{MPa} \mathrm{H}_{2}$ at room temperature. The reaction was carried out at $453 \mathrm{~K}$ for $4 \mathrm{~h}$ with a stirring speed of $800 \mathrm{rpm}$. After reaction, the organic product was collected and analyzed by GC-MS using an added internal standard, as presented in Supplementary Fig. 32. For reaction at $523 \mathrm{~K}$, $87.2 \mathrm{mg}$ WIBO was used and the other parameters were kept identically. The reaction was carried out at $523 \mathrm{~K}$ for $15 \mathrm{~h}$. The reaction products were analyzed by GC-MS, as presented in Supplementary Fig. 33.

The mass of lignin-derived phenols and furans in the WIBO and alkanes in the product were determined by internal standard. The corresponding response factors were determined by analyzing mixtures of those pure, commercial compounds of phenols, furans and alkanes, and internal standard with given weights. Mass yields of alkanes were calculated by the equation: mass of alkanes/mass of dried WIBO input. Carbon yields were calculated by the equation: mass of carbon in alkanes/ mass of carbon in the WIBO input.

Gel permeation chromatography. GPC measurements were performed on a Shimadzu LC-20AD instrument using MALLS detector. Two Mixed Bed PSS SDV linear S columns were used in series with tetrahydrofuran (THF) as mobile phase with flowing rate of $1.0 \mathrm{~cm}^{3} \mathrm{~min}^{-1}$ at $303 \mathrm{~K}$. The MALLS detector was calibrated using a polystyrene standard. The sample was prepared by dissolving WIBO in THF with $1 \mathrm{wt} \%$ concentration and then filtering with $0.20 \mu \mathrm{m}$ pore size microfilter.

Thermogravimetric analysis (TGA). TGA measurements were performed on a Mettler Toledo TGA/DSC 1 system. $16.76 \mathrm{mg}$ of sample was heated in a corundum crucible between 423 and $973 \mathrm{~K}$ at a heating rate of $5 \mathrm{~K} / \mathrm{min}$ in a flowing $50 \%$ $\mathrm{O}_{2} / \mathrm{N}_{2}$ mixture

TMPO-adsorbed sample preparation for ${ }^{31} \mathrm{P}$ MAS NMR spectroscopy. $100 \mathrm{mg}$ of the catalyst was placed in a home-made glass tube, activated at $298 \mathrm{~K}$ for $2 \mathrm{~h}$ under vacuum $\left(10^{-1} \mathrm{~Pa}\right)$, mixed with a $\mathrm{CH}_{2} \mathrm{Cl}_{2}$ solution containing $0.1 \mathrm{M}$ TMPO under nitrogen, treated by ultrasound for $1 \mathrm{~h}$ (for equilibrium), and then the solvent was evacuated under vacuum. Finally, the sample tube was sealed for storage and transferred to Bruker $4 \mathrm{~mm} \mathrm{ZrO}_{2}$ rotor with a Kel-F endcap in a glove box under nitrogen atmosphere before NMR spectroscopy measurement.

${ }^{31}$ P MAS solid-state NMR spectroscopy experiments. Solid-state MAS NMR spectroscopy experiments were carried out using a Bruker Avance III 400WB spectrometer at room temperature. To remove the effect of proton spins on quantitative ${ }^{31} \mathrm{P}$ spectra (i.e., Fig. 4a), a strong radio frequency field (B) is usually applied at the resonance frequency of the non-observed abundant spins $\left({ }^{1} \mathrm{H}\right.$ herein), which contribute to the coupling of both spin species. The high power decoupling was thus used for the quantitative ${ }^{31} \mathrm{P}$ analysis. Considering the long relaxation time of ${ }^{31} \mathrm{P}$ nuclei in NMR spectroscopy experiment, $30^{\circ}$ pulse with 1.20 $\mu \mathrm{s}$ width and $15 \mathrm{~s}$ delay time. The radiofrequency for decoupling was $59 \mathrm{kHz}$. The spectral width was $400 \mathrm{ppm}$, from 200 to $-200 \mathrm{ppm}$. The number of scanning was 800 and spinning frequency was $10 \mathrm{kHz}$. The ${ }^{31} \mathrm{P}$ chemical shifts were reported relative to $85 \%$ aqueous solution of $\mathrm{H}_{3} \mathrm{PO}_{4}$, with $\mathrm{NH}_{4} \mathrm{H}_{2} \mathrm{PO}_{4}$ as a secondary standard $(0.81 \mathrm{ppm})$. The quantitative analysis of adsorbed TMPO molecules was then calculated according to the calibration line established by running standard samples with various adsorbed TMPO concentration ${ }^{47}, 48$. On the other hand, for samples without adsorbing TMPO (Supplementary Fig. 4), the ${ }^{1} \mathrm{H}_{-}{ }^{31} \mathrm{P}$ crosspolarization was used. 
Surface area measurements. Specific surface areas were analyzed by Micromeritics Tristar II. The samples were measured for the $\mathrm{N}_{2}$ adsorption and desorption at $77 \mathrm{~K}$. Before each measurement, the samples were first in-situ degassed overnight at $110^{\circ} \mathrm{C}$ for $12 \mathrm{~h}$.

Electron paramagnetic resonance. Continuous-wave electron paramagnetic resonance (CW-EPR) was carried out in the Centre for Advanced Electron Spin Resonance (CAESR), on two spectrometers and frequencies. X-band measurements (ca. $9.4 \mathrm{GHz}$ ) were performed on a Bruker BioSpin EMXmicro spectrometer with a Bruker SHQE-W cylindrical $\mathrm{TE}_{011}$-mode resonator. The temperature was controlled with an Oxford Instruments ITC-503 cryostat and ESR-900 cryostat. W-band measurements (ca. $94 \mathrm{GHz}$ ) were performed on a Bruker BioSpin EleXsys E680 spectrometer with a Bruker EN600-1021H cylindrical $\mathrm{TE}_{011}$-mode resonator. The temperature was controlled with an Oxford Instruments ITC-503 cryostat and CF-935O cryostat. For W-band, the microwave frequency was $93.9373 \mathrm{GHz}$ for $\mathrm{W}$-band, microwave power $40 \mu \mathrm{W}$, modulation amplitude $10 \mathrm{G}$, with a sweep of 84 s over $450 \mathrm{mT}$. For X-band, the microwave frequency was $9.38914 \mathrm{GHz}$, microwave power $4 \mathrm{~mW}$, modulation amplitude $6 \mathrm{G}$, with a sweep of $41 \mathrm{~s}$ over $80 \mathrm{mT}$. The field modulation frequency was $100 \mathrm{kHz}$ at both microwave frequencies. Data analysis was performed in Matlab, and EPR simulations employed the EasySpin toolbox ${ }^{49}$.

In temperature-dependent X-band EPR measurements the sample does not undergo microwave power saturation down to $20 \mathrm{~K}$, while measurements present here were acquired at $85 \mathrm{~K}$. Quantitative X-band CW-EPR measurements determined a total spin concentration of $9.1 \times 10^{16} \mathrm{spins} / \mathrm{mg}$, and doubleintegration of best-fit $\mathrm{W}$-band simulations shows that the $\mathrm{Mo}^{5+}$ accounts for $80 \%$ of EPR-active species. W-band simulations employed a g-strain linewidth model of $\sigma_{\perp}=0.0054$ and $\sigma_{\|}=0.0079$, which the same as at X-band. Simulations uncertainties are estimated in g-values as $+/-0.001$ and hyperfine as $+/-5 \mathrm{MHz}$. Hyperfine values reported as $A\left({ }^{95} \mathrm{Mo}\right)$ are those of ${ }^{95} \mathrm{Mo}(15.9 \%$ natural abundance), while the ${ }^{97} \mathrm{Mo}$ isotope (9.56\% natural abundance) is related to ${ }^{95} \mathrm{Mo}$ by the ratio of nuclear g-factors $\left(-0.3734\left({ }^{97} \mathrm{Mo}\right) /-0.3657\left({ }^{95} \mathrm{Mo}\right)\right)$.

For EPR results, at $94 \mathrm{GHz}, \mathrm{W}$-band (Supplementary Fig. 22), a signal consistent with six-coordinate $\mathrm{Mo}^{5+}$ is resolved from oxygen vacancies at $g=2$ and donor defects at $g=1.977$ with an axial g-matrix of $g_{\perp}=1.933$ and $g_{\|}=1.884^{50}$ Natural abundance ${ }^{95 / 97} \mathrm{Mo}^{5+}$ hyperfine in X-band (Supplementary Fig. 23), 9.4 $\mathrm{GHz}$, point to at least two species in the precursor, which are similar to two of three components in the $\mathrm{H}_{2}$-reduced form, but with about one-fourth overall EPR intensity in the precursor. A third component of reduced catalyst arises as an additional $g_{\|}$feature at $g \sim 1.90$ and an additional component of hyperfine in the high field $A_{\|}\left({ }^{95 / 97} \mathrm{Mo}\right)$ feature, as demarcated in Supplementary Fig. 24 . The Wband sample, aged under air, results in a relative reduction of the $g=1.90$ feature, indicating that the corresponding site is likely surface-exposed. Multi-component simulations in Supplementary Fig. 24 also show an increase in $g_{\| l}$ from the precursor value by $\Delta g$ of ca. 0.0025 upon reduction, on the trend of increasing ionic ligand character.

\section{Superconducting quantum interference device (SQUID) magnetometry.}

Magnetic susceptibility measurements of powdered samples of catalyst before and after $\mathrm{H}_{2}$ reduction were carried out using a Quantum Design MPMS-5 SQUID magnetometer at a field of $0.1 \mathrm{~T}$ and different temperatures $(2-300 \mathrm{~K})$. Accurately weighed samples (ca. $60 \mathrm{mg}$ ) were placed into gelatine capsules and then loaded into nonmagnetic plastic straws before being lowered into the cryostat. No corrections were made for the diamagnetic contribution to the magnetic moment due to the excess silica, and it was assumed the paramagnetic contribution originated solely from $\mathrm{Mo}^{5+}$ present in the sample, as determined by ICP-MS. Hence, a total magnetic susceptibility per Mo is reported. For quick comparison the magnetic susceptibility (per Mo) at $2 \mathrm{~K}$, for catalyst before and after reduction is $6.73 \times 10^{-4}$ and $1.19 \times 10^{-3} \mathrm{~cm}^{3} \mathrm{~mol}^{-1}$, respectively, demonstrating the formation of more $\mathrm{Mo}^{5+}$ in the catalyst after $\mathrm{H}_{2}$ reduction.

Temperature programmed reduction. TPR was performed on Micromeritics AutoChem II 2920 using a flow of $\mathrm{H}_{2}$ in $\mathrm{N}_{2}\left(10 \%, 50 \mathrm{~mL} \mathrm{~min}^{-1}\right)$ ramping from 309 to $1073 \mathrm{~K}$ at a rate of $5.0^{\circ} \mathrm{K} \mathrm{min}^{-1}$.

Diffuse-reflectance infrared Fourier transform spectroscopy. DRIFT spectroscopy studies were performed using a Bruker Tensor 27 spectrometer fitted with a high-sensitivity MCT detector (with resolution of $4 \mathrm{~cm}^{-1}$ ) and a diffuse IR heated chamber equipped with $\mathrm{ZnS}$ window. The reduced catalyst $\left(\mathrm{Pd} / \mathrm{m}-\mathrm{MoO}_{3}-\mathrm{P}_{2} \mathrm{O}_{5} /\right.$ $\mathrm{SiO}_{2}$ ) and reduced $\mathrm{Pd} / \mathrm{SiO}_{2}$ with mass of $20 \mathrm{mg}$ were pre-treated in the presence of $5 \% \mathrm{H}_{2}$ in $\mathrm{Ar}$ at $383 \mathrm{~K}$ for $1 \mathrm{~h}$. The oxidized catalyst and oxidized $\mathrm{Pd} / \mathrm{SiO}_{2}(\mathrm{PdO} /$ $\mathrm{SiO}_{2}$ ) with a mass of $20 \mathrm{mg}$ were pre-treated in air at $573 \mathrm{~K}$ for $1 \mathrm{~h}$ and then cooled down to $383 \mathrm{~K}$. The $\mathrm{ZnS}$ window was kept being heated to avoid phenol condensation. After the pre-treatments, the background was scanned in the presence of $\mathrm{He}$ at $383 \mathrm{~K}$ and then the spectra were collected in the presence of phenol/helium mixture at $383 \mathrm{~K}$. The background and spectra were recorded at a resolution of 4 $\mathrm{cm}^{-1}$ with 128 accumulation scans.
Data availability. Data that support the findings of this study are available within the article (and its Supplementary Information files) and from the corresponding authors on reasonable request.

Received: 16 December 2016 Accepted: 11 July 2017

Published online: 19 September 2017

\section{References}

1. Huber, G. W., Iborra, S. \& Corma, A. Synthesis of transportation fuels from biomass: chemistry, catalysts, and engineering. Chem. Rev. 106, 4044-4098 (2006).

2. Corma, A., Iborra, S. \& Velty, A. Chemical routes for the transformation of biomass into chemicals. Chem. Rev. 107, 2411-2502 (2007).

3. Czernik, S. \& Bridgwater, A. V. Overview of applications of biomass fast pyrolysis oil. Energy Fuels 18, 590-598 (2004).

4. Bridgwater, A. V. Catalysis in thermal biomass conversion. Appl. Catal. A 116, 5-47 (1994).

5. Mohan, D., Pittman, C. U. \& Steele, P. H. Pyrolysis of wood/biomass for bio-oil: a critical review. Energy Fuels 20, 848-889 (2006).

6. Roman-Leshkov, Y., Chheda, J. N. \& Dumesic, J. A. Phase modifiers promote efficient production of hydroxymethylfurfural from fructose. Science $\mathbf{3 1 2}$ 1933-1937 (2006).

7. Huber, G. W., Chheda, J. N., Barrett, C. J. \& Dumesic, J. A. Production of liquid alkanes by aqueous-phase processing of biomass-derived carbohydrates. Science 308, 1446-1450 (2005).

8. Mehdi, H. et al. Integration of homogeneous and heterogeneous catalytic processes for a multi-step conversion of biomass: from sucrose to levulinic acid, gamma-valerolactone, 1,4-pentanediol, 2-methyl-tetrahydrofuran, and alkanes. Top. Catal. 48, 49-54 (2008).

9. Kunkes, E. L. et al. Catalytic conversion of biomass to monofunctional hydrocarbons and targeted liquid-fuel classes. Science 322, 417-421 (2008).

10. Vispute, T. P., Zhang, H. Y., Sanna, A., Xiao, R. \& Huber, G. W. Renewable chemical commodity feedstocks from integrated catalytic processing of pyrolysis oils. Science 330, 1222-1227 (2010).

11. Zhao, C., Kou, Y., Lemonidou, A. A., Li, X. \& Lercher, J. A. Highly selective catalytic conversion of phenolic bio-oil to alkanes. Angew. Chem. Int. Ed. 48, 3987-3990 (2009).

12. Zhao, C. \& Lercher, J. A. Upgrading pyrolysis oil over Ni/HZSM-5 by cascade reactions. Angew. Chem. Int. Ed. 51, 5935-5940 (2012).

13. Yan, N., Yuan, Y., Dykeman, R., Kou, Y. \& Dyson, P. J. Hydrodeoxygenation of lignin-derived phenols into alkanes by using nanoparticle catalysts combined with Bronsted acidic ionic liquids. Angew. Chem. Int. Ed. 49, 5549-5553 (2010)

14. Xia, Q. N. et al. $\mathrm{Pd} / \mathrm{NbOPO}_{4}$ multifunctional catalyst for the direct production of liquid alkanes from aldol adducts of furans. Angew. Chem. Int. Ed. 53, 9755-9760 (2014).

15. Zhao, C., He, J. Y., Lemonidou, A. A., Li, X. B. \& Lercher, J. A. Aqueous-phase hydrodeoxygenation of bio-derived phenols to cycloalkanes. J. Catal. 280, 8-16 (2011).

16. Wang, L. et al. Mesoporous ZSM-5 zeolite-supported Ru nanoparticles as highly efficient catalysts for upgrading phenolic biomolecules. ACS Catal. 5, 2727-2734 (2015).

17. Luska, K. L., Migowski, P., El Sayed, S. \& Leitner, W. Synergistic interaction within bifunctional ruthenium nanoparticle/SILP catalysts for the selective hydrodeoxygenation of phenols. Angew. Chem. Int. Ed. 54, 15750-15755 (2015).

18. Yan, N. et al. Selective degradation of wood lignin over noble-metal catalysts in a two-step process. ChemSusChem 1, 626-629 (2008).

19. Xia, Q. et al. Direct hydrodeoxygenation of raw woody biomass into liquid alkanes. Nat. Commun. 7, 11162 (2016).

20. Liu, P. X. et al. Photochemical route for synthesizing atomically dispersed palladium catalysts. Science 352, 797-801 (2016).

21. Qiao, B. et al. Single-atom catalysis of $\mathrm{CO}$ oxidation using $\mathrm{Pt}_{1} / \mathrm{FeO}_{\mathrm{x}}$. Nat. Chem 3, 634-641 (2011).

22. Zhang, B. et al. Stabilizing a platinum ${ }_{1}$ single-atom catalyst on supported phosphomolybdic acid without compromising hydrogenation activity. Angew. Chem. Int. Ed. 55, 8319-8323 (2016).

23. Zhang, W. et al. Hydrodeoxygenation of lignin-derived phenolic monomers and dimers to alkane fuels over bifunctional zeolite-supported metal catalysts. ACS Sustainable Chem. Eng. 2, 683-691 (2014).

24. Santagneli, S. H. et al. Structural studies of $\mathrm{NaPO}_{3}-\mathrm{MoO}_{3}$ glasses by solid-state nuclear magnetic resonance and raman spectroscopy. J. Phys. Chem. B 111, 10109-10117 (2007).

25. Koudelka, L. et al. Structural study of $\mathrm{PbO}-\mathrm{MoO}_{3}-\mathrm{P}_{2} \mathrm{O}_{5}$ glasses by Raman and NMR spectroscopy. J. Non-Crystal. Solids 357, 2816-2821 (2011).

26. Wang, H. et al. In operando X-ray absorption fine structure studies of polyoxometalate molecular cluster batteries: polyoxometalates as electron sponges. J. Am. Chem. Soc. 134, 4918-4924 (2012). 
27. Ressler, T., Wienold, J., Jentoft, R. E. \& Neisius, T. Bulk structural investigation of the reduction of $\mathrm{MoO}_{3}$ with propene and the oxidation of $\mathrm{MoO}_{2}$ with oxygen. J. Catal. 210, 67-83 (2002).

28. Eyssler, A. et al. On the dtate of Pd in perovskite-type oxidation catalysts of composition $\mathrm{A}(\mathrm{B}, \mathrm{Pd}) \mathrm{O}_{3 \pm \delta}(\mathrm{A}=\mathrm{La}, \mathrm{Y} ; \mathrm{B}=\mathrm{Mn}, \mathrm{Fe}, \mathrm{Co})$. Chem. Mater. 24, 1864-1875 (2012).

29. Funke, H., Scheinost, A. C. \& Chukalina, M. Wavelet analysis of extended X-ray absorption fine structure data. Phys. Rev. B 71, 094110 (2005).

30. Zheng, A., Huang, S. J., Liu, S. B. \& Deng, F. Acid properties of solid acid catalysts characterized by solid-state ${ }^{31} \mathrm{P}$ NMR of adsorbed phosphorous probe molecules. Phys. Chem. Chem. Phys. 13, 14889-14901 (2011).

31. Zhao, Q. et al. Discernment and quantification of internal and external acid sites on zeolites. J. Phys. Chem. B 106, 4462-4469 (2002).

32. Prasomsri, T., Shetty, M., Murugappan, K. \& Román-Leshkov, Y. Insights into the catalytic activity and surface modification of $\mathrm{MoO}_{3}$ during the hydrodeoxygenation of lignin-derived model compounds into aromatic hydrocarbons under low hydrogen pressures. Energy Environ. Sci. 7, 2660-2669 (2014).

33. de Souza, P. M. et al. Role of keto intermediates in the hydrodeoxygenation of phenol over Pd on oxophilic supports. ACS Catal. 5, 1318-1329 (2015).

34. de Souza, P. M. et al. Effect of zirconia morphology on hydrodeoxygenation of phenol over $\mathrm{Pd} / \mathrm{ZrO}_{2}$. ACS Catal. 5, 7385-7398 (2015).

35. Bridgwater, A. V. Review of fast pyrolysis of biomass and product upgrading. Biomass Bioenergy 38, 68-94 (2012).

36. Ingram, L. et al. Pyrolysis of wood and bark in an auger reactor: physical properties and chemical analysis of the produced bio-oils. Energy Fuels 22 614-625 (2008)

37. Routray, K., Barnett, K. J. \& Huber, G. W. Hydrodeoxygenation of pyrolysis oils. Energy Tech. 4, 1-15 (2016).

38. Nolte, M. W., Zhang, J. \& Shanks, B. H. Ex situ hydrodeoxygenation in biomass pyrolysis using molybdenum oxide and low pressure hydrogen. Green Chem. 18, 134-138 (2016).

39. Ravel, B. \& Newville, M. ATHENA, ARTEMIS, HEPHAESTUS: data analysis for $\mathrm{X}$-ray absorption spectroscopy using. IFEFFIT J. Synchrotron Rad. 12, 537-541 (2005).

40. Koningsberger, D. C. \& Prins, R. X-Ray Absorption: Principles, Applications, Techniques of EXAFS, SEXAFS, and XANES (John Wiley and Sons, 1988).

41. Rehr, J. J. \& Albers, R. C. Theoretical approaches to X-ray absorption fine structure. Rev. Mod. Phys. 72, 621-654 (2000).

42. Joly, Y. X-ray absorption near-edge structure calculations beyond the muffintin approximation. Phys. Rev. B 63, 125120 (2001).

43. Bunau, O. \& Joly, Y. Self-consistent aspects of X-ray absorption calculations. J. Phys. Condens. Matter 21, 345501 (2009).

44. Kresse, G. \& Furthmuller, J. Efficient iterative schemes for ab initio total-energy calculations using a plane-wave basis set. Phys. Rev. B 54, 11169-11186 (1996).

45. Kresse, G. \& Joubert, D. From ultrasoft pseudopotentials to the projector augmented-wave method. Phys. Rev. B 59, 1758-1775 (1999).

46. Perdew, J. P. et al. Restoring the density-gradient expansion for exchange in solids and surfaces. Phys. Rev. Lett. 100, 136406 (2008).

47. Peng, Y. K. et al. Trimethylphosphine-assisted surface fngerprinting of metal oxide nanoparticle by ${ }^{31} \mathrm{P}$ solid-state NMR: a zinc oxide case study. J. Am. Chem. Soc. 138, 2225-2234 (2016).

48. Kreissl, H. T. et al. Niobium oxides: correlation of acidity with structure and catalytic performance in sucrose conversion to 5-hydroxymethylfurfural. $J$. Catal. 338, 329-339 (2016).

49. Stoll, S. \& Schweiger, A. EasySpin, a comprehensive software package for spectral simulation and analysis in EPR. J. Magn. Reson. 178, $42-55$ (2006).

50. Louis, C. \& Che, M. EPR investigation of the coordination sphere of $\mathrm{Mo}^{5+}$ ions on thermally reduced silica-supported molybdenum catalysts prepared by the grafting method. J. Phys. Chem. 91, 2875-2883 (1987).

\section{Acknowledgements}

H.D. thanks SCG Chemicals Co., Ltd and SCG Packaging Co., Ltd for funding. J.D. acknowledges support from the National Natural Science Foundation of China (Grant No. 11605225) and the Jianlin Xie Foundation of the Institute of High Energy Physics, Chinese Academy of Sciences. Q.W. and J.F. thank State Key Laboratory of Chemical Resource Engineering for funding. W.K.M. is supported by the UK EPSRC 281 (EP/ L011972/1, grant to CAESR, the Centre for Advanced Spin Resonance). A.F.R.K. and J.-C.B. thank SCG Chemicals Co., Ltd for funding. A.F.R.K. thanks Wadham College Oxford for a RJP Williams Junior Research Fellowship. We also thank Hefei Light Source and Shanghai Light Source for use of the instruments. We thank Dr Nicholas H. Rees for performing the solid-state NMR spectroscopy; Drs Ashley Shepherd and Robert Jacobs for their help with TPR and BET measurements, Dr Yang He, Jinglu Huang, and Qu Chen for their comments on TEM results, Drs Yufei Song and Wei Chen for their valuable discussion on sample characterizations.

\section{Author contributions}

H.D. conceived the idea, designed and carried out the synthesis, characterizations and catalytic reactions, analyzed the data and wrote the manuscript. J.D. and D.C. performed XAFS data analysis and DFT calculation. X.G. performed DRIFTS measurement. Y.-K.P prepared the samples for TMPO-adsorbed ${ }^{31} \mathrm{P}$ NMR measurement and analyzed the data. W.C. performed the XAFS measurement and data analysis. T.I. initiated the idea, provided WIBO and discussion. W.K.M. performed the EPR measurement and data analysis. M.-J.L. analyzed the XAFS data. N.Y. performed GPC measurement. A.F.R.K. performed the SQUID measurement and data analysis. Y.W. performed XAFS measurement. X.Z. performed the XAFS measurement. S.J. assisted with TEM characterization. Q.W. and J.F. helped with DRIFTS measurement. J.-C.B. assisted in regulating the experiments and discussion. H.C. designed DRIFTS measurement and discussed results. Y.L. provided the resources for TEM characterization and XAFS measurement. S C.E.T. and D.O.H. supervised the project, helped design the experiments, analyzed the data and wrote the manuscript. All the authors commented on the manuscript and have given approval to the final version of the manuscript.

\section{Additional information}

Supplementary Information accompanies this paper at doi:10.1038/s41467-017-00596-3.

Competing interests: The authors declare no competing financial interests.

Reprints and permission information is available online at http://npg.nature.com/ reprintsandpermissions/

Publisher's note: Springer Nature remains neutral with regard to jurisdictional claims in published maps and institutional affiliations.

\begin{abstract}
(c) (i) Open Access This article is licensed under a Creative Commons Attribution 4.0 International License, which permits use, sharing, adaptation, distribution and reproduction in any medium or format, as long as you give appropriate credit to the original author(s) and the source, provide a link to the Creative Commons license, and indicate if changes were made. The images or other third party material in this article are included in the article's Creative Commons license, unless indicated otherwise in a credit line to the material. If material is not included in the article's Creative Commons license and your intended use is not permitted by statutory regulation or exceeds the permitted use, you will need to obtain permission directly from the copyright holder. To view a copy of this license, visit http://creativecommons.org/ licenses/by/4.0/.
\end{abstract}

(C) The Author(s) 2017 